\title{
Cuantificación en cerámica, ¿ejercicio especulativo o ejercicio hipotético? Las cerámicas ibéricas y púnicas en la Iliberri del siglo IV a.C. procedentes del depósito de la calle Zacatín $(\text { Granada })^{1}$
}

\section{Quantifying Pottery, Speculative Exercise or Hypothetical Exercise? Iberian and Punic Pottery at Iliberri during IV Century B.C. in Deposit from Zacatin Street (Granada)}

\author{
Andrés María Adroher Auroux \\ Universidad de Granada \\ Amparo Sánchez Moreno \\ Universidad de Granada \\ Inmaculada de la Torre Castellano \\ Arqueóloga
}

\section{RESUMEN}

La excavación en 1999 de una fosa rellena con abundante material datado en la primera mitad del siglo IV a.C. supone un importante avance en el conocimiento de la arqueología ibérica en el oppidum de Iliberri, pues amplia el ámbito periurbano a la relación tan estrecha que mantiene la ciudad con su territorio a través de la imagen del rio Darro. En este trabajo se presenta el estudio del material ibérico y púnico procedente de ese contexto, con interesantes aportaciones acerca de los sistemas de clasificación y cuantificación cerámica en arqueología protohistórica.

\section{SUMMARY}

Digging in 1999 fossa filled in with an archaeological material from the first half of 4th century $\mathrm{BC}$ was found; this would be a mean advance to knowledge about Iberic oppidum

${ }^{1}$ El presente estudio así como todo el proceso que dura ya casi una década, ha sido posible exclusivamente por el esfuerzo económico que han realizado los miembros del equipo que han colaborado en el mismo, pues éste no ha sido objetivo de ninguna subvención. Particularmente nos gustaría dar las gracias a Encarnación Pérez Rodríguez, quien ha dedicado varios años al remontado de las piezas, sin su participación el análisis del depósito hubiera resultado totalmente infructuoso; asimismo a Ana $\mathrm{M}^{\mathrm{a}}$ Cárdenas y $\mathrm{M}^{\mathrm{a}}$ Isabel Mancilla, quienes estuvieron al principio del proyecto, y a los que han estado al final rematando un estudio que ha durado poco más de ocho largos y cansados años: José Carlos Coria, Francisco de P. Espejo, Juan A. González, Julia Hurtado, Carmen Luzón, Judit Martín, Cintia Moreno, Daniel Moreno, Belén Ortiz, Enrique Peregrín, Juan Antonio Rojas, Andrés Roldán, Agustín Roldán y Justo F. Sol. of Iliberri because of the enlarge of periurban space until the landscape throunght the close relationship between the city and the idea of Darro river. In this paper we show the Iberic and Punic pottery from this context, with a very interesting contributions to quantifying and classification pottery systems in protohistorical archaeology.

PALABRAS CLAVES: Protohistoria; Andalucía; depósito sagrado; comensalidad; clasificación; tipología.

KEY WORDS: Protohistory; Andalusia; Sacred Deposit; Commensality; Classification; Typology.

\section{INTRODUCCIÓN}

En 1999, durante una excavación de urgencia realizada en la granadina calle Zacatín, en el casco histórico de la ciudad ${ }^{2}$, si bien fuera de lo que fue el asentamiento prerromano, sito en el barrio

${ }^{2}$ La excavación fue realizada por la empresa malagueña T.I.A., quienes publicaron el correspondiente informe en el Anuario Arqueológico Andaluz (Rambla Torralvo, Cisneros García 2000) y una ulterior nota en la Revista de Arqueología (Rambla Torralvo, Salado Escaño 2002). Nosotros accedimos al conjunto una vez éste fue depositado en el Museo Arqueológico Provincial, mediante un permiso de estudio de materiales a nombre de una de nosotros (Inmaculada de la Torre) pasando en el 2014 a nombre de otro (Andrés María Adroher Auroux), por lo que no contamos con ningún tipo de analítica de sedimentación ni de materia orgánica. 
del Albaicín (Adroher Auroux et alii 2001; Adroher Auroux et alii 2005; Barturen Barroso 2008), se localizó un conjunto de material sobre el cual se han dado algunas noticias pero todas ellas relativamente incompletas (Pachón Romero 1997-1999; Rambla Torralvo y Cisneros García 2000; Rambla Torralvo y Salado Escaño 2002; De la Torre Castellano 2005; De la Torre Castellano 2008; Rouillard y de la Torre Castellano 2014) pero que parece corresponderse con un depósito votivo, o bien el resultado de un ritual cuyo ajuar fue ulteriormente vertido a una especie de favissa o bothros junto al recorrido del río Darro.

El conjunto está compuesto por un numeroso grupo de cerámicas (casi 5000 fragmentos con un peso que alcanza prácticamente los 40 kilogramos), de procedencia griega, púnica e ibérica y material metálico, hueso trabajado, huevo de avestruz, arcilla cocida y elementos de pasta vítrea.

En el año 2005 iniciamos el estudio del material cerámico, mediante un proceso de clasificación, asignación tipológica y agrupación por individuos, partiendo de la propuesta de que todo este material representaba una acción unitaria funcional y cronológicamente; esta labor nos ha llevado prácticamente siete años, pues el índice de alteración de los fragmentos es enorme, pensando que, desde la deposición del mismo en la fosa junto al río, éste ha ido erosionando durante 24 siglos las zonas de fracturación de las distintas fracciones, dificultando notablemente las posibilidades de unir dos fragmentos rotos contiguos.

El conjunto de material extraído durante aquella excavación de urgencia es tan enorme que resulta prácticamente imposible presentar un estudio de materiales completo en un artículo de revista, por lo que hemos decidido repartir diversas publicaciones en dos fases; en primer lugar hace tiempo iniciamos la publicación del material por naturaleza y clases. Ya en 2005 se realizó una exposición en el Museo Arqueológico y Etnológico de Granada de los ungüentarios en pasta vítrea (Vílchez Vílchez et alii 2005); recientemente se publicaron las copas de pie alto de figuras rojas áticas (Rouillard y De la Torre Castellano 2014), y tras el presente en que nos centramos en los materiales ibéricos y semitas, le seguirán dos más sobre las cerámicas griegas (barnices negros por un lado y figuras rojas por otro), y varios sobre los objetos dependiendo de su naturaleza, siempre dentro de líneas editoriales que garanticen una correcta gestión a nivel de impacto. Para un segundo momento preparamos varios artículos de carácter interpretativo que destinaremos a congresos internacionales para que este impacto se amplíe lo más rápidamente posible y a la mayor cantidad de público científico en el menor tiempo. En los artículos del primer conjunto cada caso se trata de forma dis- tinta para enfocar adecuadamente la problemática que plantea cada uno de ellos en la historiografía, de modo que puedan ser utilizados para enfrentarse a problemas específicos dependiendo del conjunto de material que se esté analizando. Por otra parte no se ha considerado, por el momento, la posibilidad de publicar todo el material en una sola monografía por dos problemas. En primer lugar la situación de crisis que impide enfrentarse económicamente a una obra que, vista la calidad y cantidad del material arqueológico recuperado, precisa de un grueso volumen, y no podemos olvidar que se trata de un hallazgo resultante de una excavación de urgencia, no de un proyecto de investigación, por lo que no es fácil encontrar financiación adecuada. Por otra parte pensamos que conforme los materiales se vayan dando a conocer a la comunidad científica el interés por este depósito crecerá y podrá realizarse una publicación monográfica con más posibilidades de éxito y con la calidad en las imágenes que requiere este descubrimiento.

Planeando este proceso en la publicación del depósito creemos que podemos garantizarla disponibilidad a cualquier investigador de la totalidad de los datos acerca de uno de los conjuntos de materiales griegos más importantes de todo el Mediterráneo, pero que tiene un contexto del que no podemos dejar de ofrecer la mayor cantidad de datos posible para que la comunidad científica pueda reflexionar por sí misma ante este fenomenal hallazgo.

\section{EL OPPIDUM IBÉRICO DE ILIBERRI}

En el corazón del granadino barrio del Albaicín se ubicó el oppidum ibérico de Iliberri, posteriormente convertido en municipio romano posiblemente ya en época cesariana.

A pesar de las múltiples intervenciones arqueológicas realizadas desde 1982 en adelante, muy poco se ha publicado en relación a las fases ibéricas de ocupación del yacimiento, tema que normalmente se comenta de forma un poco tangencial.

Contamos con dos libros sobre el Carmen de la Muralla (Sotomayor Muro et alii 1984; Roca Roumens et alii 1988), otros dos sobre las intervenciones del Callejón del Gallo (Adroher Auroux y López Marcos 2001) y Santa Isabel la Real (López López 2001), dos más de estudios de conjunto, con marcado carácter historiográfico (Rodríguez Aguilera 2001; Orfila Pons 2011) y un catálogo de exposición (Orfila Pons 2008) y de los cuales solamente el del Callejón del Gallo propone un análisis arqueográfico y arqueológico de la totalidad de los datos con que se cuenta en ese momento sobre el oppidum ibérico, ya que los dos 
libros generalistas se centran el primero en la historia de la arqueología reciente, independientemente de los resultados, y el segundo se centra en la ciudad romana, al igual que sucede con la exposición sobre Florentia Iliberritana (Orfila Pons 2008). A finales del siglo pasado (Casado Millán et alii 1998) y en la primera década del siglo XXI (Adroher Auroux et alii 2005; Barturen Barroso 2008) se publican los tres únicos artículos que se centran en el análisis de parte o la totalidad de los datos con que contamos sobre el desarrollo de Iliberri ibérica.

No obstante esta falta de datos y análisis las excavaciones han ido permitiendo visualizar estructuras y materiales que dejan entrever un oppidum de grandes dimensiones, con una red urbana definida por varios lienzos de muralla correspondientes a varios períodos, encerrando una superficie que podría situarse en unas 15 hectáreas (Fig. 1).

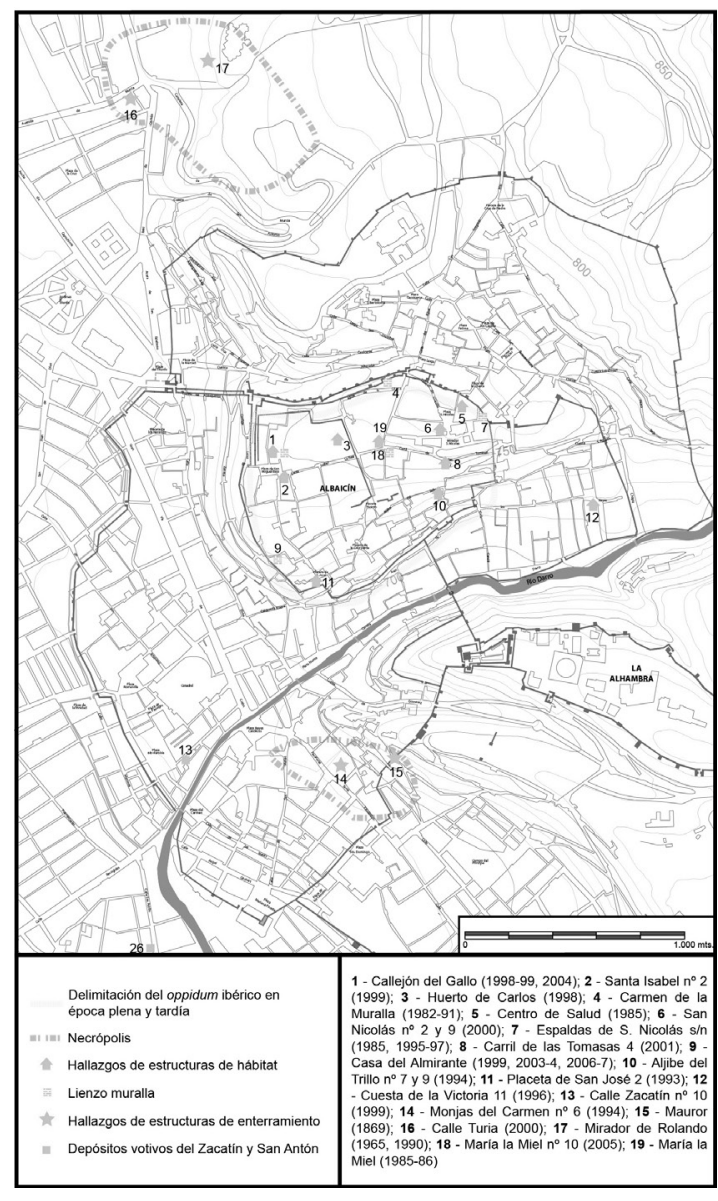

Figura 1. Plano de la ciudad de Granada con la localización de los hallazgos de época protohistórica y la delimitación aproximada del antiguo oppidum ibérico de Iliberri (elaboración propia).
Al igual que en otros oppida coetáneos granadinos (Basti en Baza, Tutugi en Galera o Arkilakis en Puebla de Don Fadrique), se han documentado, al menos, dos necrópolis que coexisten desde, como mínimo, el Ibérico Pleno. La del Mirador de Rolando es la mejor conocida (Arribas Palau 1967); aunque la mayor parte de los materiales publicados relacionan dicha necrópolis con el siglo IV a.C., las excavaciones más recientes demuestran que se extiende en el espacio y en el tiempo largamente, desde, al menos, el siglo vi a.C. (Caballero Cobos 2008), y perdurando claramente hasta época romana (Pastor Muñoz y Pachón Romero 1991; Pastor Muñoz y Pachón Romero 1992), y a tenor de los materiales que fueron recogidos por Arribas a mediados de los años 60 del pasado siglo xx entre los cuales aún se conserva el borde de una fuente Hayes 99 en terra sigillata africana D (siglo V-VI d.C.); se trata pues de la necrópolis septentrional de Iliberri.

Pero el oppidum está delimitado por otra necrópolis, situada al Sur, al otro lado del río Darro. Se conoce gracias a Gómez-Moreno, y estaría situada en la llamada colina del Mauror; se recogieron en su momento solamente dos urnas ${ }^{3}$, a las cuales pensamos que se pueden añadir el hallazgo en 1995 de otros ejemplares en la calle Monjas del Carmen, situada a los pies de dicha colina; algunas de las urnas que hemos podido ver pertenecen a época antigua (siglo vI a.C.), lo que permite considerar que ambas necrópolis se fundan prácticamente en la misma época, aspecto que resulta muy interesante a la hora de comprender la articulación social de la estructura clánica de Iliberri.

Por otra parte, existe un último hallazgo aislado que tuvo lugar en la calle San Antón ${ }^{4}$ en los años 70 del pasado siglo $\mathrm{xx}$; se trata de un conjunto muy homogéneo y completo compuesto, entre otros, de varios platos, algunos cubiletes de paredes finas y cerámica común, de modo que podría datarse en el siglo iI o muy inicios del siglo I a.C.; según varios autores se trataría de otro ámbito de necrópolis, pero hay tres aspectos que la alejan de esta interpretación; en primer lugar la lejanía respecto al oppidum, superior a un kilómetro; además se sitúa en la misma vertiente que éste rompiendo el esquema de separación de un

\footnotetext{
${ }^{3}$ Una de ellas, la número CE03087, se puede consultar en las referencias que se hacen en la nota 4.

${ }^{4}$ Los objetos de este hallazgo casual entre la Calle San Antón y Alhamar de Granada se pueden consultar en la Web domus del Portal de Museos y Conjuntos Arqueológicos de la Junta de Andalucía Museo Arqueológico de Granada <http:// www.juntadeandalucia.es/culturaydeporte/WEBDomus/ busquedaAvanzada.do ? acron = MAEGR\&lng=es $>$ o a través de la página del Ministerio de Cultura (http://ceres.mcu.es) haciendo una búsqueda general por calle San Antón (última visita 08/08/2014).
} 
río entre hábitat y espacio funerario tan propio del paisaje periurbano bastetano ${ }^{5}$; en tercer lugar entre el material localizado no aparecen urnas, elementos necesarios dentro del ajuar de enterramiento propio del mundo ibérico, aunque sea de fase tardía. Más adelante volveremos sobre este conjunto.

Igualmente se conocen algunas estructuras públicas (o comunitarias) como el depósito de agua de la calle Álamo del Marqués (Lozano Rodríguez et alii 2008), con un complejo sistema constructivo que demuestra un profundo conocimiento de las características físicas y químicas de la naturaleza petrológica de las rocas, ya que tratándose de una estructura hidráulica no presenta el característico revoco de las cisternas a bagnerolle propias del mundo ibérico (véase el importante conjunto del Cerro de la Cruz de Almedinilla en Córdoba), y sin embargo el agua no se perdería entre los mampuestos utilizados, ya que la tensión superficial de las moléculas de agua unido a las microperforaciones características de las roca travertínica provoca que se taponen dichas oquedades; por otra parte, el material utilizado para unir los sillarejos es arcilla pura, manteniendo así la especificidad hidrófuga de la superficie del contenedor.

A pesar de éstos y otros hallazgos aún es necesario un buen estudio del conjunto del hábitat; apenas sabemos que se funda a partir de la agrupación de un poblamiento del Bronce Final disperso en su territorio, hacia finales del primer cuarto del siglo VII a.C. a juzgar por los resultados de las excavaciones en el Callejón del Gallo y en Callejón de las Tomasas (Martín López et alii 2004); este primer poblado estaría rodeando de una cerca de no más de un metro de anchura. Posteriormente (entre los siglos VII y VI a.C.), al igual que sucede con los grandes oppida bastetanos (Adroher Auroux y Caballero Cobos 2012), sufre una profunda transformación monumentalizándose en un sistema defensivo bien documentado en la zona de San Nicolás, cuyo tramo nororiental se conservaba en una longitud de unos 30 metros, con alzado mayor de 4 metros y anchura entre 5 y 7,5 metros a los que sumar el talud que en la base llega a los 2 metros (Casado et alii 1998).

\section{EL DEPÓSITO DE LA CALLE ZACATÍN}

Como comentamos anteriormente (vs. supra) uno de los hallazgos más espectaculares en relación con

${ }^{5}$ A diferencia de otros ámbitos donde hábitat y necrópolis pueden localizarse en la misma unidad geomorfológica; incluso en algún caso bastetano podemos ver este fenómeno, salvo que en nuestro territorio representa más una excepción que no la regla. las fases ibéricas de Iliberri se produjo en 1999 durante una intervención arqueológica de urgencia en la céntrica calle Zacatín, al pie del Albaicín (Fig. 2). Se trata de un depósito, ubicado en las inmediaciones del río Darro, compuesto por un numeroso conjunto de materiales rellenando una estructura negativa, sin relación con ningún conjunto estructural próximo conocido.

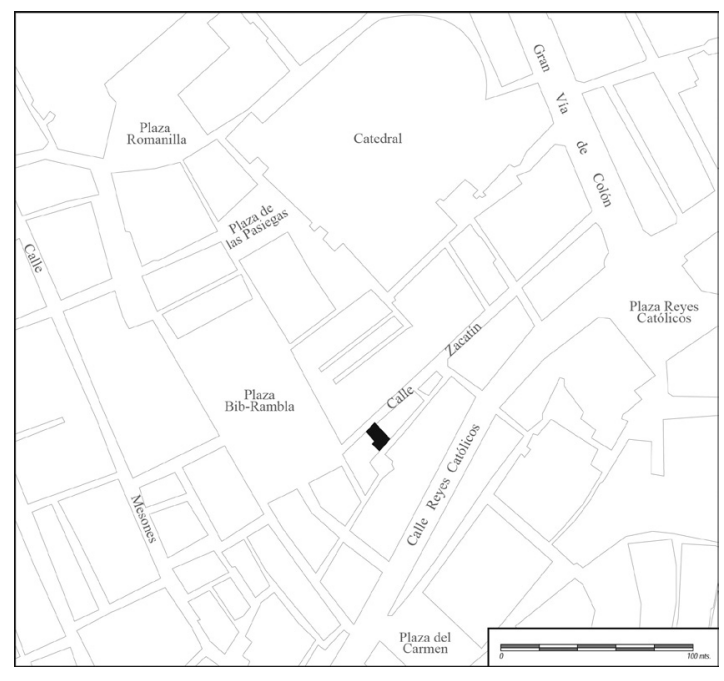

Figura 2. Ubicación del solar en el que se realizó la excavación arqueológica donde apareció el depósito (elaboración propia).

La excavación afectaba a un solar de dimensiones muy reducidas (no alcanza ni $80 \mathrm{~m}^{2}$ ), y a dos metros y medio de profundidad se localizó casi en la esquina nororiental una fosa rectangular, muy plana, de 1,10 metros de anchura y más de 1,20 de longitud (se metía por debajo del solar contiguo por lo que desconocemos el valor total de esta medida), sin que se apreciara buzamiento, y con un espesor de unos $25 \mathrm{~cm}$ de media, embutida en una serie estratigráfica formada por alternancia de sedimentos arenosos y limo-arcillosos, propios del paleocanal del río Darro, cuyo lecho actual se encuentra a apenas veinte metros al Sureste de este punto El depósito no parecía presentar ningún tipo de preparación o elemento estructural alguno, tratándose de una simple fosa excavada en los depósitos fluviales, o al menos eso se desprende de la lectura de los informes consultados. En algún momento parece que el fuego debió tener algo que ver con el ritual, ya que aparecen muchas piezas con alteraciones térmicas y a pesar de que el material se depositó relativamente lavado al museo, hay un plato de barniz negro que se guardó con gran cantidad de carbones; lo único que podemos adelantar es que 
el fuego se produjo después de la fragmentación de las piezas, ya que un gran número de ellas están quemadas por los perfiles de fragmentación, lo que podría interpretarse de dos maneras, o bien se quemó el material tras el acto de depositarlo, o bien se quemó durante el ritual y, posteriormente, se arrojó a la fosa con parte del carbón utilizado en la combustión; carecemos de datos por el momento para saber cuál fue el proceso con precisión.

De este depósito se extrajo una gran cantidad de material y de diversa naturaleza. Entre otros omnipresente el conjunto de cerámicas es numéricamente abrumador (como se dijo anteriormente, 40 kilogramos de peso repartidos en casi cinco millones de fragmentos) y púnicas, a lo que se suma material metálico, (de bronce contamos con un soporte trípode, una pieza en forma de serpiente, un fragmento de una fíbula anular hispánica, y algunos anillos, siendo de hierro algunos fragmentos de clavos y otros elementos difícilmente reconocibles), arcilla cocida (seis fusayolas y media y dos piezas discoidales recortadas sobre cerámica común ibérica), una placa de hueso grabada con iconografía orientalizante, varios fragmentos de una vieira, un tubo corto de hueso (quizás una bisagra), diversos fragmentos de huevo de avestruz, y, en pasta vítrea, algunos fragmentos de cuentas de collar y un nutrido grupo de ungüentarios, que, aunque aún no restaurados, suponen más de una veintena de piezas repartidas entre alabastrones, oinochoes y anforiscos, además de numerosos fragmentos difícilmente clasificables (El Amrani Paaza 2005).

En el ámbito cerámico contamos con un total de 4.904 fragmentos que tienen un peso total de 39.643 gramos. Un breve análisis de los tres ámbitos de procedencia de esos materiales observamos que más de dos terceras partes son producciones de origen griego (cerámicas áticas de figuras rojas y de barniz negro) con 3434 fragmentos (70,02\%) y 28307 gramos $(71,40 \%)$; casi un tercio son cerámicas de producción ibérica (común, pintada, engobe rojo, cocina y ánforas), concretamente 1462 fragmentos (29,81\%) que pesan 11164 gramos $(28,16 \%)$, mientras que las producciones de ámbito púnico (común, pintadas y ánforas) son muy residuales, ya que sólo contamos con 8 fragmentos $(0,16 \%)$ que pesan apenas 172 gramos $(0,43 \%)^{6}$.

El índice de fragmentación es muy elevado (aunque un poco desigual dependiendo de los vasos), lo

\footnotetext{
${ }^{6}$ Plantear desarrollar sistemas de corrección o de validez como $\mathrm{x}^{2} \mathrm{o}$ t-student resulta poco fiable ya que se trata de una muestra aleatoria y particular, que no responde a ningún modelo conocido con el cual contrastar el valor de la distribución.
}

que nos hace sospechar que ciertos vasos fueran arrojados ya rotos o con la suficiente violencia como para que se rompieran al caer contra el fondo de la fosa ${ }^{7}$; los materiales se encuentran muy frecuentemente quemados, lo que nos permite considerar que la fosa se debió amortizar con carbones y cenizas calientes, lo cual nos indica que sufrió un proceso de combustión directo o indirecto ${ }^{8}$, es decir, identificaríamos un ritual donde el fuego jugaba un papel purificador a la vez que sellaba simbólicamente el depósito. No obstante, parece que no se hubiese producido fuego vivo sobre la fosa pues, si bien existen algunos materiales que denotan alteraciones térmicas importantes, no son muchos los fragmentos que las presentan, y éstas, inclusive, no son excesivamente intensas como para haber estado sometidas a un fuego vivo directo 9 .

Desde un punto de vista arqueográfico existen dos importantes problemas a la hora de analizar el complejo ritual que tuvo lugar en ese sitio hace dos mil cuatrocientos años: en primer lugar, éste no ha sido excavado en su totalidad, por lo que desconocemos el nivel de representatividad del material recuperado respecto al conjunto general del depósito. Y, por otra parte, al estar situado junto al río Darro, en las terrazas holocénicas de éste, se ha ido produciendo un proceso de desgaste hídrico en la zona de fracturación de las piezas como consecuencia del microtransporte laminar de agua que sucede en los lechos fluviales, y que ha provocado que, el ya de por sí duro esfuerzo de clasificación de miles de fragmentos de piezas amortizadas con violencia, se le una el que las zonas de fractura presentan una acusado nivel de erosión que impide asociar, en muchas ocasiones, un fragmento a otro (Fig. 3).

Ésta es la primera publicación que pretende ser sistemática sobre una parte del material extraído en la excavación del depósito; dada la extensión del material en cantidad y en calidad, unido a su complejidad, así como la necesidad de publicarlo por completo,

\footnotetext{
${ }^{7}$ No será en este trabajo sino el específicamente relacionado con la cerámica griega de figuras rojas donde demostraremos este punto, ya que afecta particularmente a las kylix, cuyo índice de fragmentación es notablemente superior al resto del material localizado en el depósito.

${ }^{8}$ Bien se quemó directamente o por el contrario, se rellenó de cenizas de un hogar próximo, quizás el utilizado como acompañamiento en el mismo ritual previo al enterramiento final del mismo.

${ }^{9}$ Recordamos que no podemos realizar analíticas porque la casi totalidad del material depositado en el museo consiste en artefactos, aunque se conserva un plato de barniz negro con algunos cabrones y sobre el cual realizaremos diversas analíticas como carpología y $\mathrm{C} 14$, y existen restos de cinco huesos, que no están calcinados, por lo que no pertenecerán seguramente al depósito; al margen de ellos no hay ningún otro elemento que permita realizar analíticas de carácter paleoclimático.
} 


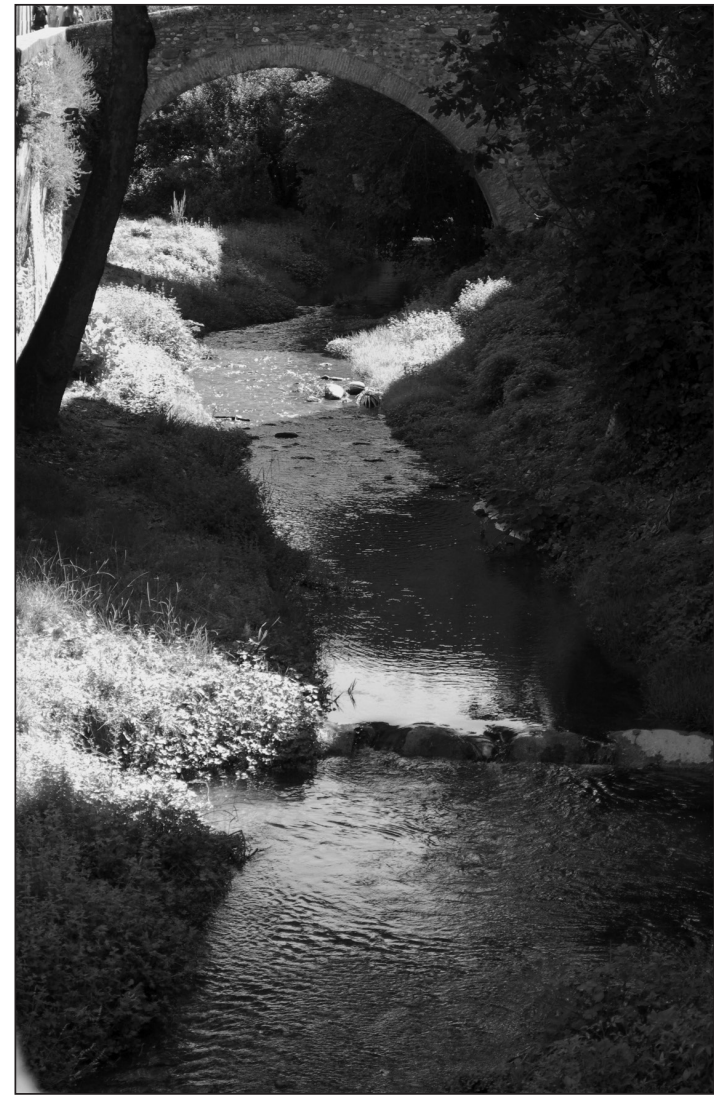

Figura 3. Imagen actual del río Darro a su paso por la falda meridional del Albaicín (foto: autores).

consideramos que en este primer trabajo avanzaremos solamente el estudio de los materiales cerámicos no áticos, conjunto ya de por sí suficientemente interesante por tratarse de una agrupación homogénea tanto desde el punto de vista cronológico como funcional, al formar parte de un ritual cerrado, aislado estructuralmente y monofásico.

A pesar de lo anteriormente expuesto, existen algunos fragmentos que no se corresponden exactamente con la cronología del depósito; hay que tener en cuenta un problema importante y de difícil solución a nivel analítico que es la propia naturaleza de los procesos postdeposicionales y su injerencia en un contexto teóricamente cerrado; una vez se formase el depósito los procesos que lo alterarían en mayor medida estarían relacionados con las crecidas y bajadas del río, pues por un lado transporta material ajeno al conjunto (procedente de los arrastres desde el hábitat situado río arriba apenas a 300 metros) y lo deposita sobre él, o incluso por subsidencia puede incorporarlo a la unidad estratigráfica que lo caracteriza mezclándolo de esta forma al material que forma parte sistémica del depósito; al mismo tiempo, éste sufre un fenómeno de erosión, y no sabemos si una parte más o menos importante del mismo se ha podido perder arrastrado río abajo. Por tanto, se produce un doble sesgo a la hora de establecer lo que falta por un lado y los incorporado con posterioridad por otro. Eso explicaría que tengamos por ejemplo un borde y el arranque de las asas de un pithos del siglo viI a.C., algunos bordes de urnas del mismo momento, o incluso un fondo de talón de una olla del Bronce Final, materiales a todas luces intrusivos en el contexto expuesto; por el otro extremo explica igualmente la presencia de material romano, como copas de vidrio o fragmentos de terra sigillata hispánica.

En algunos casos ha sido fácil detectar las intrusiones, por tratarse de piezas claramente más antiguas que la datación del depósito (intrusión negativa, Morillo y Adroher Auroux 2014: 29-30) pero más difícil resulta cuando el índice de negatividad es muy bajo, o casi inexistente; por supuesto cuando se trata de intrusiones positivas no existe ningún problema, cual es el caso de los materiales romanos anteriormente mencionados.

Por otra parte tenemos algunas piezas que estratigráficamente son en todo contemporáneas al material que compone el ritual, pero que podrían, no obstante, no formar parte del mismo. Se trata de un conjunto de bordes de urnas y de ánforas, algunos con un fuerte índice de erosión, y que se documentaron en los mismos niveles del depósito inicial. Es probable que ese material estuviera ya incluido a modo de clastos en la terraza del río que se excavó para meter el material, por lo que se revolvió con las piezas que efectivamente fueron arrojadas en el interior, pues el índice de erosión que presentan es muy elevado, como veremos a continuación.

\section{METODOLOGÍA, MÉTODO, TÉCNICAS Y OB- JETIVOS}

El depósito cuya publicación sistemática iniciamos con este artículo está en relación directa con el hábitat, aunque se ubique extramuros; ninguna relación debe tener con una necrópolis ${ }^{10}$, ya que los restos de enterramientos se ubican a una notable distancia de este punto y, además, no presentan ninguna correlación cronológica con este conjunto.

${ }^{10}$ Las propuestas que eventualmente pueden leerse acerca de un paralelo de este depósito con el silicernium de la tumba 19 de Hoya Gonzalo no tiene suficiente base, ya que ni la cronología ni el contexto permiten equiparar ambos casos (Casado Millán y Orfila Pons 2011: 39). 
Como dijimos anteriormente en este trabajo nos centraremos en una parte del material, concretamente las producciones cerámicas ibéricas y feno-púnicas.

El material indígena recuperado es extraordinariamente interesante, por su alta homogeneidad y porque proporciona nuevas propuestas acerca de la composición del ajuar propio de un ritual ibérico.

Las piezas nos las encontramos agrupadas sin ordenación alguna, sin separación posible, y gran parte del material había sido lavado a mano y con cepillo, aunque en muchos casos no se hayan retirado apenas las concreciones calcáreas que afectan a la superficie de muchos fragmentos; la extracción de estas concreciones, previo a nuestro acceso al material, provoca que se hayan perdido muchas cubriciones y tratamientos, particularmente visible en las cerámicas ibéricas de engobe rojo, como veremos a lo largo del presente texto.

La cerámica forma parte de dichos rituales y por ende, si decodificamos adecuadamente la información que contiene podremos generar un conocimiento adecuado que nos aproxime al difícil mundo de la espiritualidad.

Como ya se apuntó la fragmentación y la erosión de las piezas son dos de los principales problemas a que nos enfrentamos, de modo que uno de los principales objetivos es conocer la cantidad de vasos que formaron parte de este conjunto. Para ello hemos intentado desarrollar y aplicar los diversos sistemas de cuantificación actualmente conocidos en la historiografía ceramológica.

Si bien cada vez está más claro que es necesario un sistema unificado de cuantificación de materiales en arqueología, no es fácil poner de acuerdo a muchos investigadores, lo que demuestra el escaso desarrollo que en nuestra disciplina se está demostrando en el trasvase de datos que permitan hablar del mismo problema en situaciones similares, de modo que podamos establecer modelos interpretativos.

Parte de este problema deviene de la falta de formación de muchos investigadores en problemas relacionados con la estadística, que sigue siendo un factor importante a la hora de despreciar sistemas de cuantificación unificados; por otra parte, aún subsiste en algunos proyectos de investigación una raquítica idea de lo científico como un elemento oculto, donde o bien los datos no deben ser publicados por considerar la Arqueografía (analítica) como la hermana menor de la Arqueología (interpretativa), y que solamente se debe publicar interpretación, ya que la publicación de los documentos es más propia de un positivismo hoy tan denostado. No hay que olvidar un tercer elemento importante, y es que para una parte de la Academia, someterse a los protocolos asumidos por la comu- nidad es identificado como una notable pérdida de la independencia, lo que no deja de reflejar un aún presente complejo de inferioridad parecido al que la arqueología demostró con los métodos cientifistas de algunas arqueologías procesalistas, que intentaban "elevar" la arqueología a la categoría de "ciencia".

Como diría el mismo Martínez Fernández (2012: 52), muchos de nosotros, en nuestra disciplina, consideramos que "el lenguaje es una imagen suficientemente fiel de la realidad", lo que llevaría implícito que la realidad es cognoscible, y, por tanto, existe. Así pues estudiaríamos un pasado que existe en la actualidad, no, como se desprendería de cualquier análisis que supere los postulados del positivismo más rancio, que el pasado no es más que una proyección del presente, y las evidencias que han llegado hasta nosotros se han incorporado al presente en cuanto a tal, no en cuanto pasado.

Es por ello que el discurso que se desarrolla desde nuestra disciplina debe estar basado en el registro, en la asunción de que tal registro no es una lectura del pasado, sino un constructo cultural actual, sobre el cual, para llegar a entendernos, a construir un discurso, sólo nos queda fijar protocolos para que dicho discurso sea inteligible.

En nuestro caso, y en relación con el contexto arqueológico, contamos con varios imponderables que presentan difícil solución y que pasamos de describir:

A. El índice de fragmentación, muy elevado, y que impide una correcta formulación en la identificación de los vasos y su ulterior remontado;

B. El índice de erosión a causa de su proximidad al agua, que provoca que se haya perdido masa de las piezas por encima de las alteraciones más frecuentes en contextos arqueológicos en tierra;

C. Las alteraciones por tensión térmica, provocadas por la acción del fuego (vivo o no) sobre el conjunto del material, de forma no homogénea, lo que provoca que las piezas cambien de color no pudiendo utilizarse éste como indicativo (ni siquiera aproximado) de la pertenencia de dos fragmentos al mismo vaso o no;

D. El espacio de trabajo y almacenamiento, ya que tan ingente cantidad de material necesita una constante revisión (después de siete años en la actualidad seguimos encontrando fragmentos aislados que pueden asociarse a algunos de los vasos parcialmente remontados);

E. La representatividad del depósito, ya que al localizarse en una excavación de urgencia correspondiente a un solar, parte de aquél está aún enterrado en el solar contiguo, y no hay forma de conocer el porcentaje del material recuperado respecto al total, por lo que no podremos hacernos una idea de la representatividad de los vasos en el ritual, lo que resolveremos consi- 
derando hipotéticamente que no hubo diferenciación espacial a la hora de arrojar este conjunto vascular a la fosa tras la celebración del mismo;

F. Iigualmente partimos de la idea de que los fragmentos localizados no han sufrido ninguna alteración particular previa a su deposición (o en consecuencia de su uso), por lo que la totalidad del material se corresponderá con algún elemento que jugaba su papel en esta acción, por lo que no deben existir elementos sueltos, lo cual resulta complejo ya que visto el índice de fragmentación y de erosión no siempre es fácil detectar el material intrusivo en el conjunto del material contextualizado;

G. Por último, y en relación con lo anterior, este contexto no es frecuente, puesto que se trata de un depósito cuyas características (al igual que sus contextos homofuncionales en todos los casos) son particulares, ya que se trata de un conjunto plenamente contextualizado, que debe entenderse (al igual que una tumba) como objetos en sí y cuya significancia están en la relación que establecen los objeto uno a uno respecto al resto del conjunto (material que pudiera haber servido tanto para contexto de santuarios, como funerarios como domésticos juegan un papel distinto por la asociación con el resto de las piezas).

Desde los años 70 del pasado siglo xx una de las principales preocupaciones de la ceramología arqueológica ha consistido precisamente en elaborar un sistema o protocolo universal que permita reconstruir el número de vasos con los que nos encontramos a partir de los fragmentos que componen el registro arqueológico.

Desde que en 1973 Egloff planteó los protocolos para la construcción del EVE (acrónimo inglés de estimación de equivalencia de vasos) hasta la actualidad han sido muy numerosas las propuestas y que se aplican a diversas situación (distintos contextos, diferentes respuestas) así como a diversos niveles en la jerarquía del estudio del conjunto cerámico (categoría, clase o tipo); algunos de los más utilizados en la actualidad siguen siendo, por un lado el EVE (modificado y perfeccionado por Orton 1993 con bibliografía anterior) y por otro, el número mínimo de individuos. Algunos recientes congresos han vuelto a poner el énfasis en las necesidades de establecer protocolos avanzando en el conocimiento y en los métodos y técnicas adecuados a cada caso (Arcelin y Truffeau-Libre 1998; Horejs et alii 2010; Verdan et alii 2011), existiendo continuas propuestas y evoluciones. Concretamente en ceramología protohistórica y clásica el peso, que en líneas generales había pasado a un segundo plano, ha vuelto a valorarse notablemente especialmente en relación con los estudios anfóricos, especialmente con las aportaciones de Jaume Molina (Molina Vidal 1997) y César Carreras (Carreras Monfort 2000), con novedosas propuestas que incluyen peso, índice de fragmentación y volumen de tierra excavado en diferentes módulos.

Ciertos sistemas no han sido útiles en nuestro contexto, como el número mínimo de individuos (NMI) o el número tipológico de individuos (NTI), pues el conjunto vascular presenta muy poca variedad tipológica. Y además sería igual que aplicar el sistema a un contexto de ajuar funerario, no da un resultado comparable a nada (por la propia naturaleza del contexto, poco frecuente de por sí).

Por ese motivo hemos optado por utilizar la idea de lote, de modo que agrupe los fragmentos potenciando todos los aspectos en relación con la decoración, el tipo y las uniones de fractura posibles. Utilizaremos dicho concepto simplemente como método de agrupación, pero la cuantificación final se realizará con el sistema EVE $^{11}$ (Fig. 4), es decir, con el sumatorio de todos los segmentos de círculo que compongan todos los bordes o todos los fondos con que contamos asignables a una categoría, una clase, una forma o un tipo, dependiendo del nivel jerárquico al que nos refiramos en un momento dado.

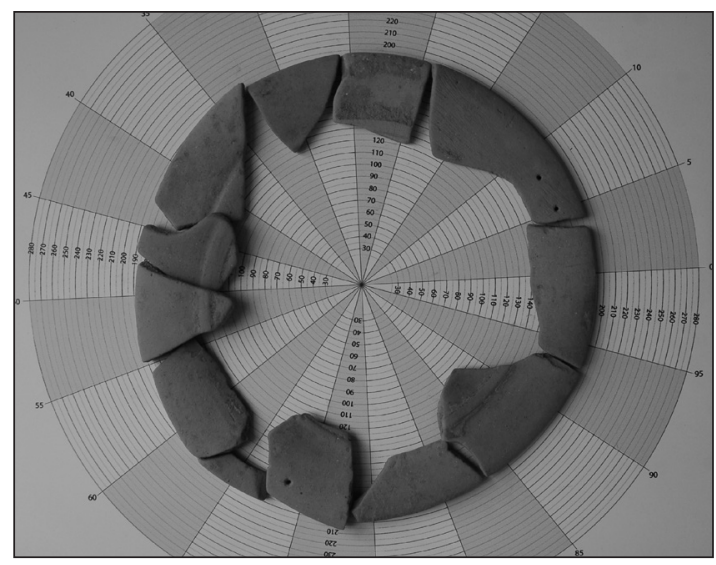

Figura 4. Ejemplo de cuantificación mediante el sistema EVE del lote ZAC-353 (BRI P134) (foto: autores).

Por otro lado debemos indicar que utilizaremos el peso, ya que agrupado al número de fragmentos nos

${ }^{11}$ Existen diversas opciones de estimación de vasos, bien a partir del borde (e.b.), del fondo (e.f.), aunque la cuantificación de EVE más extendida se calcula a partir de la mitad de la suma de las dos variables anteriores (e.b + e.f. / 2). Por otra parte Orton y Tyers (1993) desarrollaron un sistema que mejoraba sensiblemente el estudio a través de la cuantificación de PIE (acrónimo inglés de equivalentes de información de vasos) pero la aplicación informática desarrollada (pie-slice) ha quedado algo en desuso. Recientemente existen algunos ensayos para optimizar este sistema de cálculo de covarianza, pero no ha tenido mucho éxito (Alzola Romero 2005-2006). 


\begin{tabular}{|c|c|c|c|c|c|c|c|c|}
\hline grupos & ánfora & porcentaje & común & porcentaje & fina & porcentaje & totales & porcentaje \\
\hline fragmentos & 37 & $2,52 \%$ & 940 & $63,95 \%$ & 493 & $33,54 \%$ & 1470 & $100 \%$ \\
\hline bordes & 4 & $1,13 \%$ & 72 & $20,40 \%$ & 277 & $78,47 \%$ & 353 & $100 \%$ \\
\hline asas & 1 & $25,00 \%$ & 3 & $75,00 \%$ & 0 & $0,00 \%$ & 4 & $100 \%$ \\
\hline fondos & 0 & $0,00 \%$ & 25 & $30,86 \%$ & 56 & $69,14 \%$ & 81 & $100 \%$ \\
\hline amorfos & 32 & $3,10 \%$ & 840 & $81,40 \%$ & 160 & $15,50 \%$ & 1032 & $100 \%$ \\
\hline peso & 1.689 & $14,90 \%$ & 6.194 & $54,64 \%$ & 3.453 & $30,46 \%$ & 11.336 & $100 \%$ \\
\hline estimación bordes & 0,63 & $2,55 \%$ & 5,31 & $21,53 \%$ & 18,72 & $75,91 \%$ & 24,66 & $100 \%$ \\
\hline estimación fondos & 0 & $0,00 \%$ & 8,08 & $33,84 \%$ & 15,80 & $66,16 \%$ & 23,88 & $100 \%$ \\
\hline EVE & 0,32 & $1,30 \%$ & 6,70 & $27,59 \%$ & 17,26 & $71,12 \%$ & 24,27 & $100 \%$ \\
\hline Lotes & 6 & $3,61 \%$ & 83 & $50,00 \%$ & 77 & $46,39 \%$ & 166 & $100 \%$ \\
\hline
\end{tabular}

Figura 5. Reparto del material cerámico por categorías y elementos; los porcentajes se relacionan con los grupos (deben leerse en horizontal, no en vertical).

dará indicaciones acerca del índice de fragmentación, $\mathrm{y}$, como veremos, no parece que todas las formas se hayan fragmentado de la misma manera, de modo que es probable que el ritual lleve implícito una acción de amortización especial de ciertos tipos de materiales, incluyendo una fragmentación previa al hecho de arrojar las piezas a la fosa; algo parecido a lo que ya hemos comentado en otras ocasiones que sucede con los santuarios ibéricos al aire libre documentados en el ámbito de Alta Andalucía y parte del Sureste peninsular (Adroher Auroux 2013a).

Respecto a la tipología al uso, y sin entrar en detalle acerca del problema de los sistemas de clasificación de las cerámicas ibéricas (suficientemente bien explicados en Bonet Rosado y Mata Parreño 2008), hemos utilizado la aplicación S.I.R.A. (Adroher Auroux 2013b) para las referencias tipológicas de los distinto materiales; para evitar engorrosas definiciones nos limitaremos a nombrar en cada caso las características de los tipos y la nomenclatura asignada. Igualmente a S.I.R.A. nos remitimos en relación a los diversos aspectos de clasificación y nomenclatura a él asociados.

\section{LOS MATERIALES}

En este trabajo presentaremos el estudio de las cerámicas ibéricas y púnicas presentes en el depósito de la calle Zacatín de Granada, y que suponen un total de 1470 fragmentos, repartidos entre 353 bordes, 81 fondos, 4 asas, y 1032 amorfos, con un peso de 11.336 gramos, representando un EVE de 24,27. Todos estos materiales se han repartido en un total de 166 lotes.
En el conjunto que aquí analizaremos están presentes clases cerámicas que pueden agruparse en las tres grandes categorías ${ }^{12}$, es decir, cerámica de transporte o ánforas, cerámica común (que incluye la cerámica de cocina) y la cerámica fina. No obstante el reparto es bastante desigual en lo que se refiere a la representatividad de cada una de ellas (Fig. 5).

Un problema que no hemos logrado resolver claramente es el de las intrusiones. Como dijimos más arriba existen materiales que, dada su cronología, es poco probable que pertenezcan al depósito en cuanto contexto sistémico, como algún fragmento de cerámica protoibérica (un pithoi pintado, por ejemplo); pero el material potencialmente contemporáneo resulta mucho más difícil de aislar, y, en los casos que lo hemos determinado como intrusión nos basamos fundamentalmente en el nivel de erosión que presenta la pieza o el tipo de piezas; en cada caso iremos razonando de forma específica.

\subsection{ProtohistóRICA ÁNFORA}

Es la categoría, en general, menos representada. Un total de 37 fragmentos que representan un porcentaje muy bajo (apenas $2,5 \%$ del total ${ }^{13}$ ). Se distribu-

\footnotetext{
${ }^{12}$ El concepto de categoría ha sido suficientemente desarrollado en el ámbito de la ceramología protohistórica en la definición de sistemas de clasificación como SYSLAT (Py 1997: 134): "categoría es un conjunto que reagrupa diversos tipos de cerámicas a partir de criterios técnicos o funcionales" (categorie, un ensemble regroupant plusieurs "types" de céramiques sur des critères techniques ou fonctionnels).

${ }^{13}$ Cualquier porcentaje en el texto se refiere al sustantivo del numeral precedente al que se asocia la cifra.
} 
yen en dos grandes clases, ya que tenemos la mayor parte adscrito a ánforas ibéricas y un solo fragmento de borde de ánfora púnico hispánica procedente del mediodía peninsular, concretamente una T.8.2.1.1; no se ha localizado ningún fondo de ánfora, lo que en general nos llevaría a considerar la posibilidad de que este grupo no formase parte del conjunto originalmente, pudiendo tratarse, en consecuencia, todos ellos materiales intrusivos. No obstante, hay que tener en cuenta que la tipología de todos los bordes de ánforas ibéricas son muy semejantes y por tanto podría ser contemporáneos entre sí y con el depósito.

Las ánforas ibéricas han sido productos poco estudiados en profundidad, y hasta el momento, se han resistido a cualquier sistematización tipológica que se les haya aplicado, que no sea de carácter local o regional ${ }^{14}$; esto es debido a que, a diferencia de sus homónimas apenas han viajado por el Mediterráneo, siendo el resultado de un particular efecto de las influencias fenicias hacia las comunidades del interior de la Península Ibérica. Las ánforas ibéricas han sido más objetos de almacenaje que de transporte propiamente dicho, lo cual tiene cierta lógica si pensamos que el ánfora es, tradicionalmente, un material apropiado para el comercio marítimo, pero incómodo y poco operativo para el transporte de líquidos o semilíquidos por transporte terrestre.

Los tres bordes aquí localizados (núms. 252, 253 y 254) (Fig. 6: 32, 35 y 36) representan en suma un EVE de 0,29 (e.b.=0,58; e.f.=0); sus labios son elevados, de sección rectangular y prácticamente verticales; han perdido la altura de los elementos característicos del siglo vi a.C., como puede verse en el conjunto más completo bastetano en Canto Tortoso (González Román et alii 1995), pero sin llegar a estar tan aplastados como los bordes circulares más característicos de época tardía; por tanto son claramente anteriores a la fase E4 de Callejón del Gallo, datada a finales del siglo II a.C., y cuyas ánforas ibéricas presentan un labio más rebajado (Adroher Auroux et alii 2001: Fig. 5.17.1-2). Por tanto, una cronología rondando los siglos v a III a.C. es perfectamente asumible para este conjunto de bordes. No se ha documentado ninguna perforación previa a la cocción del tipo que aparece eventualmente en los hombros y cuya funcionalidad, por el momento, se nos escapa (en su momento la

\footnotetext{
${ }^{14}$ En el caso de Granada solamente se conocen dos ejemplos de sistematización en cerámica ibérica; un estudio de carácter específico sobre ánforas (Adroher Auroux y López Mar$\cos 2000$ ) que plantea el problema de la falta de estratigrafías, y otro posterior (Román Punzón y Mancilla Cabello 2008) que intenta proponer un estudio general, pero que no plantea ni modelos tipológicos ni propuestas cronológicas concretas.
}

denominamos ánfora tipo Sierra Martilla, Adroher Auroux y López 2000).

Más complejo resulta establecer paralelos con otros conjuntos; podrían relacionarse con el tipo sudibérico V (Florido Navarro 1984), datada en los siglos VI al III a.C.; o bien el tipo 1.2.2. (ánfora con hombro redondeado odriforme) de la clasificación de Mata y Bonet (Mata Parreño y Bonet Rosado 1992: 124), que ellas datan en los siglos VI-V a.C. En Cerro Macareno (Pellicer Catalán 1983: 375-377; Pellicer Catalán et alii 1983: 85-86) encontramos paralelos en los números 1404 datada a principios del siglo IV a.C., y el 1.354, algo anterior pues se fecharía a fines del siglo v a.C. Perfiles de bordes semejantes se documentan en la fase IV de Cástulo, concretamente el fragmento 849, correspondiente al nivel II del sondeo IX, fechado en el siglo IV a.C. (Blázquez Martínez et alii 1985: 214-215). En aras a una mejor datación de nuestros ejemplares como tempus ante quem podemos fijar el siglo II a.C. a tenor del impresionante conjunto descubierto y publicado de los niveles de destrucción del Cerro de la Cruz de Almedinilla, donde el tipo más reciente (ánfora 53100) presenta ya el borde redondeado, alejándose de estos ejemplares de la Calle Zacatín (Vaquerizo Gil et alii 2001).

Un contexto muy cercano y que presenta una buena colección de materiales anfóricos con una datación relativamente homogénea, situada, grosso modo, en el siglo IV a.C. es el de Loma Linda en Ogíjares (Rodríguez Ariza 1991-1992: Fig. 6-9); aquí volvemos a observar los bordes algo elevados y de sección cuadrada con hombros no excesivamente horizontales.

No parece que este tipo de borde se extienda muy lejos de nuestra zona, ya que, por ejemplo, no se encuentra en las islas Baleares (Guerrero Ayuso, Quintana 2000), ni tampoco lo encontramos en el levante peninsular, al menos a partir de la altura de Alicante (Gailledrat y Rouillard 2000) lo que nos permitiría considerar que se trata de producciones locales o regionales.

En cuanto al ánfora púnico-hispánica se corresponde con el tipo T.8.2.1.1 (Fig. 6: 31), proveniente del ámbito meridional de la Península Ibérica; aún quedan muchas incógnitas respecto a los principales centros de producción así como a los contenidos específicos de estas ánforas (Sáez Romero 2010, con abundante bibliografía), aunque sin duda es inicialmente una producción propiamente gadirita que nace en los primeros años del siglo IV a.C., lo que no impide pensar que en épocas posteriores pudiera haber sido producida en otros centros como las costas granadinas y malacitanas. No obstante, la escasez de estas piezas en relación a las coetáneas T.12.1.1.1/2 como se detecta en el puerto púnico de Baria (López Cas- 

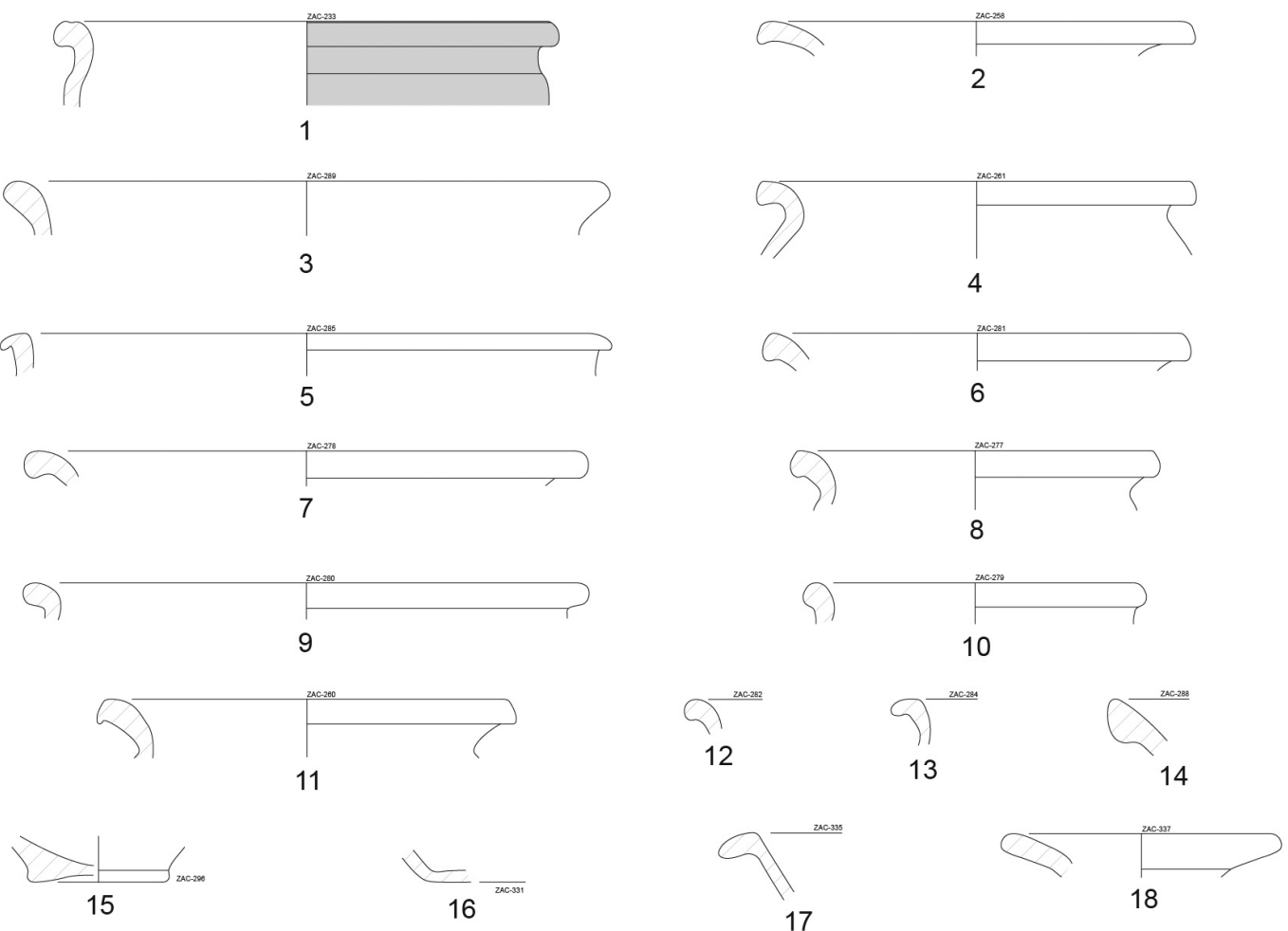

7

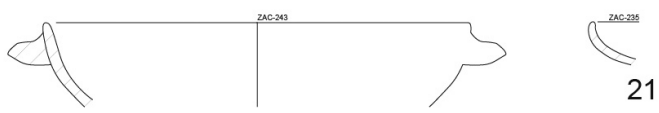

20
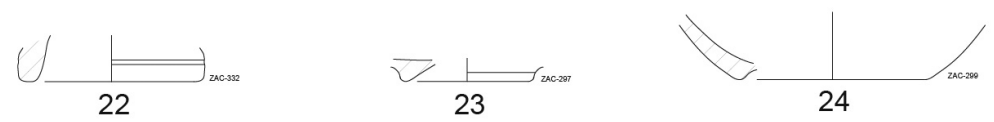

24
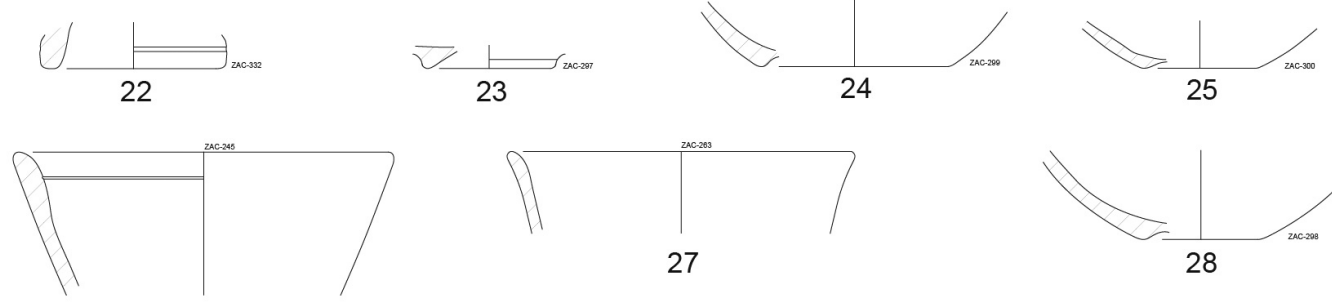

27

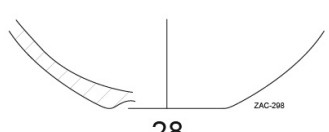

26

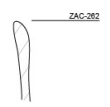

29

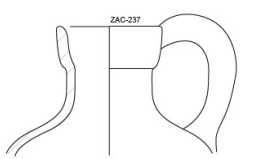

33

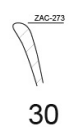

30

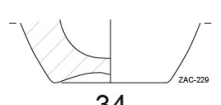

34

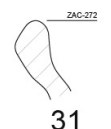

31

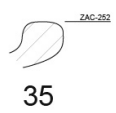

35

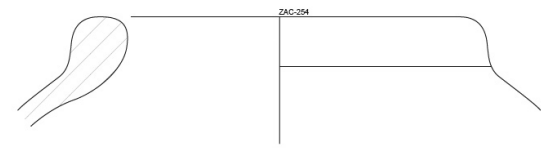

32

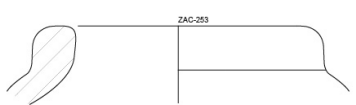

36

Figura 6. Cerámica pintada ibérica: COM-PIN Ur0 (1-3).Cerámica común ibérica: COM-IB Ur0 (4-15), COM-IB indeterminado (16), COM-IB Mt0 (17), COM-IB Bt0 (18), COM-IB Cp10 (19-20, 22-23), COM-IB Cu10 (21), COM-IB Vs0 (24-30). Ánfora ibérica (32,

35, 36). Ánfora púnica-hispánica T.8.2.1.1 (31). Cerámica común púnica: COM-PUN jarro 541 (33), COM-PUN Pl2 (34). 
tro et alii 2011; Martínez Hahnmüller 2012) podría permitirnos considerar que los materiales que llegan a las zonas de Alta Andalucía y Sureste peninsular estarían producidas en los centros alfareros gadiritas. No obstante, un atento análisis visual de la arcilla del ejemplar del Zacatín arroja un conjunto de desgrasantes propios de contextos terciarios, metamórficos, con abundante cuarcita y, sobre todo, esquistos, con cierta carencia de mica, más relacionado con el complejo alpujárride, por lo que, teniendo en cuenta que en la provincia de Granada no se han detectado por el momento evidencias de la fabricación de estos productos, podremos considerar que se trata, probablemente, de una producción de las costas malagueñas.

Algunos autores han planteado la posibilidad de que este tipo transporte vino en vez de salazones (Carretero Poblete 2007: 77), aunque se refieren especialmente a las variantes del tipo Tiñosa más que a las del tipo Carmona, con la que nuestro ejemplar presentar un mayor número de concomitancias.

La presencia de salazones de pescado en Iliberri quedó ya testimoniada en las excavaciones del Callejón del Gallo (Piques 2001), ya que en contextos del siglo VII a.C. se documentan restos de boga (Boops boops), sardina (Sardina pilchardus) y jurel (Trachurus sp.), que bien pudieron haber llegado en ánforas fenicias del tipo T.10.1.2.1 documentadas largamente en el Albaicín en relación con los contactos con las poblaciones semitas de las costas meridionales (Barturen Barroso 2008: 141), tanto en los niveles protoibéricos del Carmen de la Muralla (Roca Roumens et alii 1988; Fig. 23 y Fig. 30) o la fase E1 del Callejón del Gallo (Adroher Auroux et alii 2001b: Fig. 5.12; Fig. 5.14.1-3), ya que este tipo parece multifuncional, sirviendo tanto para el transporte de vino como de conservas de pescado.

Aunque no se recogieron muestras que pudieran permitir detectar presencia de biorrestos en el depósito de la calle Zacatín, nos inclinamos a considerar que la presencia del ejemplar hispano-púnico estaría en relación con el consumo de conservas de pescado, ya que no llegan las ánforas de las serie T.12 que pudieran completar este mercado, y, en principio, no hay otros recipientes que podamos asociar a este consumo en los contextos de Iliberri.

\subsection{PROTOHISTÓRICA COMÚN}

La cerámica común es la más frecuente en número de fragmentos (940, que componen el 63,95\% de las cerámicas que estamos analizando) el 75,00 \% de las asas y el 81,40\% de los amorfos (840 fragmentos), si bien hay que tener en cuenta que muchos de ellos han podido ser clasificados en esta clase cerámica por error insoslayable, ya que dada la calidad del engobe en la superficie de algunas piezas, que se desprende con facilidad, y un raspado poco cuidadoso para la limpieza de algunas piezas durante el proceso de excavación, como así ha sucedido, habrá provocado que piezas originalmente barnizadas hayan perdido completamente su tratamiento superficial y, por ende, hayan sido clasificadas como producciones comunes. $\mathrm{Si}$ ponderamos este problema podremos ver que, por ejemplo, en NMI, solamente representan el 20,40\% del colectivo, y su valor EVE es de 6,70 (e.b. $=53,1$; e.f. $=8,08)$.

Dentro de la cerámica común distinguiríamos cinco grandes clases: cerámica modelada a mano, de cocina, y común ibérica oxidante en cuanto a material indígena; en cuanto a común púnica tenemos productos provenientes tanto del centro del Mediterráneo como producciones propiamente hispánicas.

La cerámica a mano está representada por un solo ejemplar correspondiente a un fondo de olla de pie indicado (Fig. 10: 10), característico del Bronce Final; sin duda esta pieza no pertenece al contexto votivo, ya que se trataría de una intrusión notablemente más antigua. No cabe ninguna duda acerca de la existencia de cerámica a mano que se encuentra completamente fuera de contexto, arrastrado por las laderas que van a hacer al río Darro (Adroher Auroux et alii 1995: 319), el cual, a su vez deposita a lo largo de su cauce fragmentos de diversa índole. No entraremos tampoco en detalle pero los elementos de este tipo en contextos previos a época ibérica en el Albaicín son suficientemente conocidos (Rodríguez Aguilera 2001), por lo que no se sale de la lógica la presencia del mismo en nuestro contexto en cuanto material de arrastre.

Otra clase que representa un serio problema es el de la cerámica de cocina; parece ser que la cerámica tosca de cocina disminuye drásticamente su presencia en Iliberri a partir de finales del siglo VI a.C. según las seriaciones analizadas del Carmen de la Muralla (Roca Roumens et alii 1988). El caso es que contamos con un total de 63 amorfos con un peso de 686 gramos; ni un solo fragmento de borde ni de fondo, lo que nos hace sospechar que este material no está correctamente focalizado. Desde nuestro punto de vista habría que tener en cuenta tres aspectos que deben compaginarse entre sí. En primer lugar la total ausencia de elementos diagnóstico, posteriormente la escasa presencia de cerámicas de cocina en contextos de época pleno ibérica en Iliberri y, en tercer lugar, debemos tener en cuenta que las arcillas de las cerámicas toscas de cocina son más compactas que las arcillas de la vajilla de mesa y cerámicas finas ibéricas, por tanto deben pesar más; ante el 


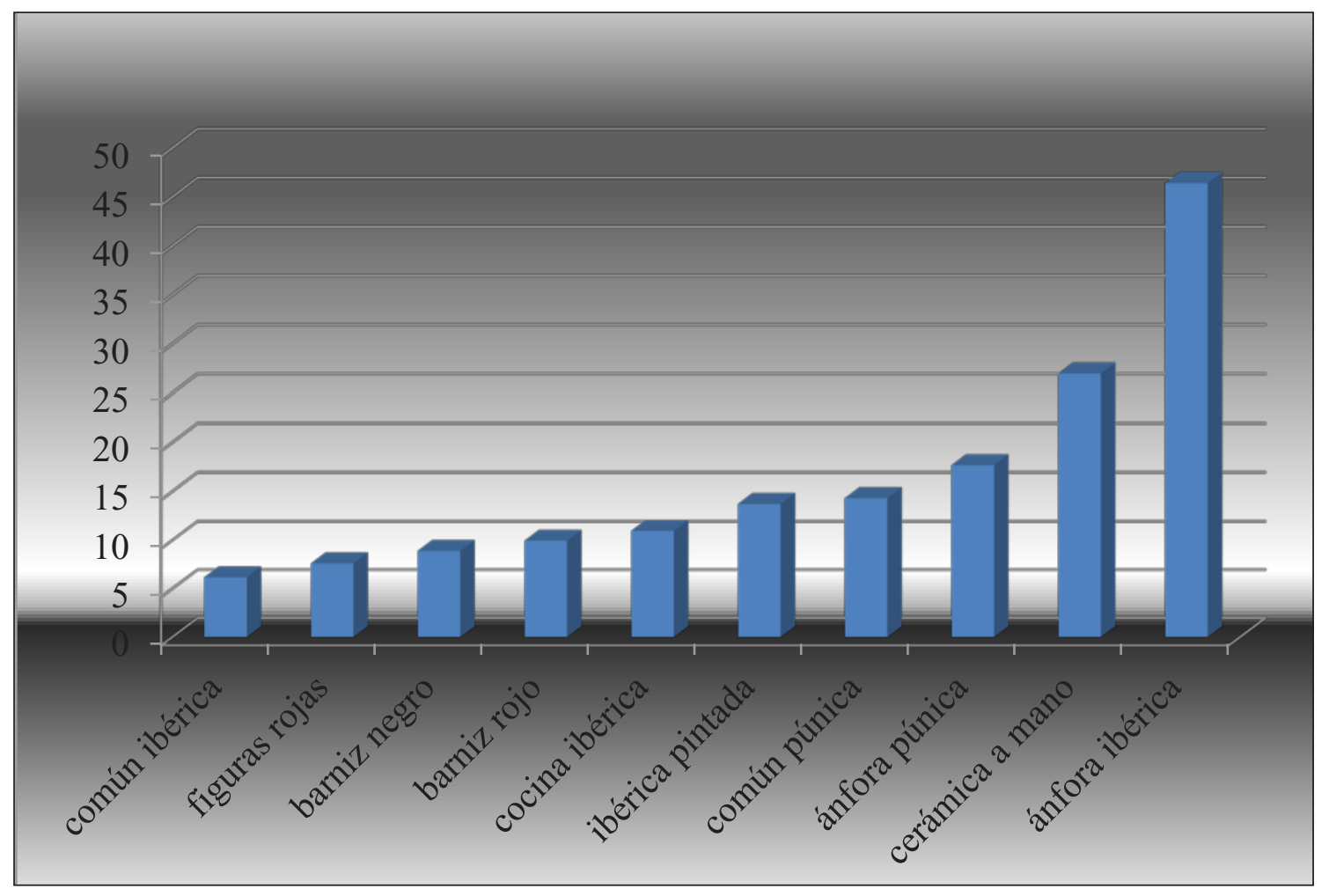

Figura 7. Peso medio por fragmento de cada clase cerámica.

mismo volumen podemos observar en el gráfico el importante peso de la cerámica a mano y, cómo al mismo tiempo, la cerámica de cocina se mantiene en medidas muy semejantes a los valores tanto de la vajilla fina como de mesa en el conjunto general del depósito; por su parte, la cerámica de cocina vuelve a aparecer con fuerza a partir de los siglos III/II a.C., siendo difícil distinguirla de la posterior cerámica de cocina romana, salvo en algunos casos concretos, así como tampoco de ciertas cerámicas medievales si no es por el contexto o por un elemento diagnóstico. Todo ello nos sugiere que el grupo considerado como cerámica de cocina, aún no habiendo sido distinguido en la excavación en otras unidades estratigráficas, parece poco probable que realmente pertenezca al depósito desde un punto de vista contextual, o que su presencia en el mismo debe ser considerada como de carácter intrusivo (Fig. 7).

Respecto a la cerámica común ibérica de cocción oxidante se plantea un problema relacionado con la particularidad de que ciertas piezas no pertenezcan al contexto, para lo cual solamente podemos basarnos en los escasos conocimientos sobre crono-tipologías que tenemos en el mundo ibérico del Sureste peninsular y Alta Andalucía. Incluyendo todos los elementos (intrusivos o no) está representado por 868 fragmentos que pesan 5.309 gramos, repartidos en 67 bordes, 2 asas, 23 fondos y 776 amorfos; su valor EVE es 5,82 (e.b. $=4,61$; e.f. $=7,03$ ), todo ello en un conjunto de 76 lotes.

Esta clase es difícil de tratar, pues como ya se dijo es probable que esté sobrevalorada según ciertos criterios, como la pérdida de decoración pintada o barnizada de ciertos fragmentos bien por erosión bien por el proceso de limpieza del material tras su recogida. De esta forma sólo nos entretendremos en los "elementos diagnóstico".

En cuanto a formas abiertas tenemos siete bordes y dos fondos que se corresponden con menos de la mitad del valor en EVE en ambos casos (0,43 de bordes y 0,45 de fondos); se trata de dos posibles casos de copas que imitan formas griegas, tipo kylix, con dos asas horizontales(núm. 244 y 243 COM-IB Cp10) (Fig. 6: 19 y 20; Fig. 9).No están engobadas ni presentan ningún tipo de decoración en la superficie a diferencia de lo que sucede con las series consideradas como imitaciones de formas griegas en época plena; llama la atención la molduración en la pared externa del pie, especialmente en el caso del núm. 332 (Fig. 6: 22). 
Solamente encontramos un pequeño fragmento de un cuenco-lucerna (núm. 235, COM-IB Cu10) (Fig. 6: 21), que podría ser perfectamente contemporáneo al contexto, si bien es cierto que suelen ser mayoritarios en contextos algo más tardíos, como sucede en el caso del nivel asociado al muro de sillarejos localizado en las primeras excavaciones del Carmen de la Muralla, concretamente el estrato III de la zona I (Sotomayor Muro et alii 1984: 27-28), datable entre los siglos III y II a.C.

Hay cinco lotes de fuentes $(\mathrm{EVE}=0,72$; e.b. $=0,10$; e.f. $=1,35)$, con un peso de 124,4 gramos. Dos de los fondos, concretamente los núm. 246 y 294 (Fig. 10: 7 y 8) son fondos planos, característicos de niveles notablemente más antiguos, que suelen iniciarse con producciones de pastas reductoras (cerámica gris ibérica antigua) y acaban produciéndose a partir de la segunda mitad del siglo VII a.C. también en ambientes oxidantes, cual es el caso de los dos ejemplares que aquí presentamos, por lo que deben ser considerados materiales ajenos al depósito. Lo mismo sucede con la pieza núm. 295 (Fig. 10: 9), que por sus características tecno-tipológicas pensamos que habría que asociarla a una intrusión romana. Los dos bordes restantes, núm. 286 y 344 (Fig. 10: 2 y 6) presentan unas arcillas muy poco depuradas, más características de niveles anteriores a la formación de este contexto.

Algo parecido sucede con los dos fragmentos que podemos adscribir a lebes; el primero de ellos, núm. 283 está tan alterado que no ha podido ser dibujado, siendo sin embargo una pieza muy espesa, lo que da a entender que ha sido fuertemente erosionada por el efecto del agua que sin duda fue arrastrada hasta este punto procedente de los derrubios de ladera del Albaicín; la segunda pieza (núm. 338) (Fig. 10: 11), si bien no tan alterada, presenta la característica arcilla poco depurada de fases anteriores, por lo que también debería ser considerada una pieza intrusiva.

Una pieza interesante es la núm. 335 (Fig. 6: 17), que se corresponde con un mortero de ala redondeada o con una fuente; aunque no puede medirse el borde (representa en torno a un $5 \%$ del mismo) parece una pieza de reducidas dimensiones y de perfil muy poco frecuente en nuestro ámbito regional.

El mayor porcentaje del material lo representan los diversos tipos de platos. Con 216 fragmentos, hay 25 bordes, 11 fondos y 180 fragmentos amorfos que se corresponden con formas abiertas. Todo ello suma un peso de $1.814,8$ gramos, y representan un EVE de 3,38 (e.b. = 1,73; e.f. $=5,03$ ), repartidos en un total de 28 lotes.

La mayor parte de los platos se asocian a formas de perfil continuo, con el borde curvo convergente (P111) (Fig. 8: 17), paralelo (P112) (Fig. 8: 18), divergente
(P113) (Fig. 8: 19-21) carenado en el tercio superior bajo el borde (P114) (Fig. 8: 22-23) o borde continuo recto divergente (P115) (Fig. 8: 24-31) ; solo tenemos dos ejemplares de platos de bordes vueltos simples (núm. 225 y 343) (Fig. 8: 32 y 33) que se corresponden con los tipos 16-C y 16-D de Pereira (1988: 169), datados todos ellos entre los siglos v y III a.C.

Puesto que resulta complicado si no imposible asociar los fondos a cualquier tipo de plato, la valoración por EVEs resulta interesante; en cuanto a los tipos propiamente dichos, los platos de borde curvo divergente (COM-IB P113) (Fig. 8: 19-21) y los de borde recto también divergente (COM-IB P115) (Fig. 8: 25-31) son mayoritarios respecto al resto; los escasos ejemplares de platos de borde carenado en el tercio superior (COM-IB P114) (Fig. 8: 22-24) en relación a los otros es, desde nuestro punto de vista, un indicio de antigüedad; de hecho existen ciertas posibilidades de que los fragmentos de platos carenados pudieran ser intrusivos en el conjunto, ya que son característicos de contextos más tardíos, cuando no propiamente romanos como evolución de los de perfil curvo, y ante la total desaparición de los de borde recto divergente a partir del finales del siglo II o inicios del siglo I a.C. En nuestro caso, además, los P115 son relativamente gruesos, pudiéndose incorporar a los perfiles propios de los platos-tapadera de las grandes necrópolis ibéricas de época plena como la de Cerro del Santuario en Baza, donde esos platos son prácticamente mayoritarios (Presedo Velo 1982).

En cuanto a formas cerradas tenemos dos grandes grupos, muy desigualmente representados: urnas y botellas.

Por un lado existe una boca de botella con borde muy saliente plano (núm. 337) (Fig. 6: 18); no localizamos formas similares, pues las paredes son gruesas lo que indica que debe tratarse de una pieza de gran tamaño.

Continuando con las cerámicas comunes ibéricas debemos hablar de las urnas ${ }^{15}$, sobre las cuales hay poca literatura en cuanto a ensayos tipológicos. Contamos con un total de 26 fragmentos, repartidos entre 21 bordes, 2 fondos de ónfalo (EVE 0,95; e.b. $=1,65$; e.f. $=0,25)$ y 3 amorfos, pesando en total 336,9 gramos, distribuidos en 21 lotes. De este grupo habría que eliminar algunas piezas; por ejemplo, las numeradas como 236, 259, 275 y 336 (Fig. 10: 4,

\footnotetext{
${ }^{15}$ Algunos autores prefieren el término tinaja, pero una lectura del diccionario de la Real Academia de la Lengua propone que ésta es un contendor para líquidos (cuando no incluso una medida de capacidad), y por el contrario, en la tercera acepción de urna no se establece ningún uso concreto, por lo cual preferimos este término menos direccional funcionalmente hablando.
} 

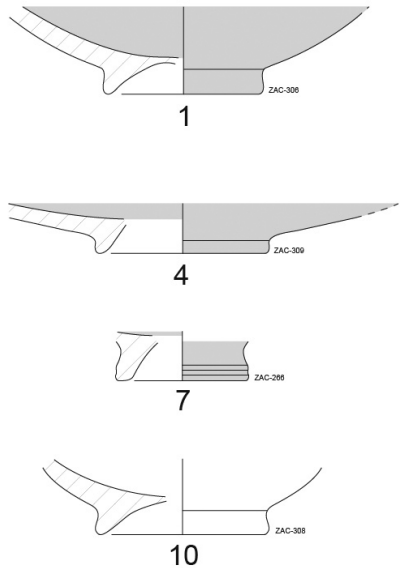
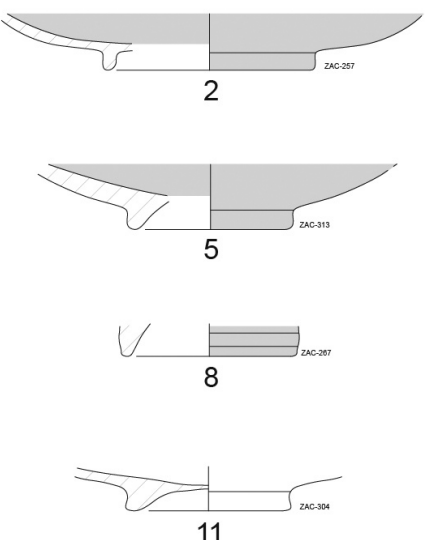
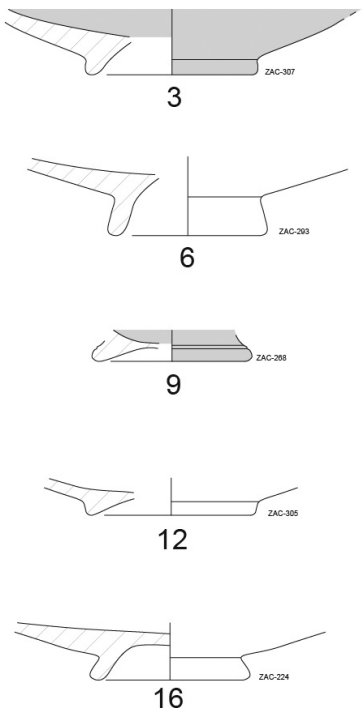

$15^{\text {20.cos }}$

14

13

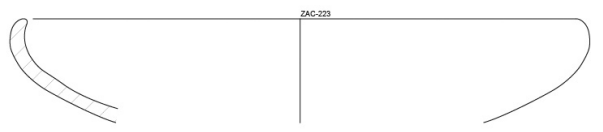

17

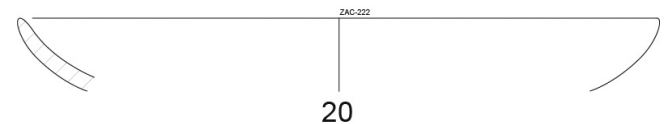

20

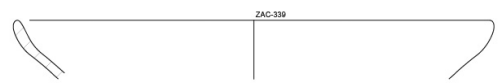

23

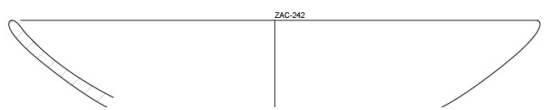

28

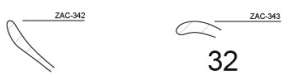

31

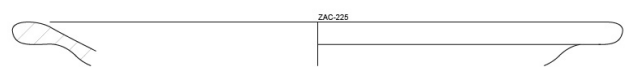

33
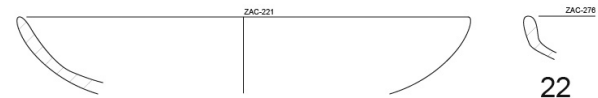

21
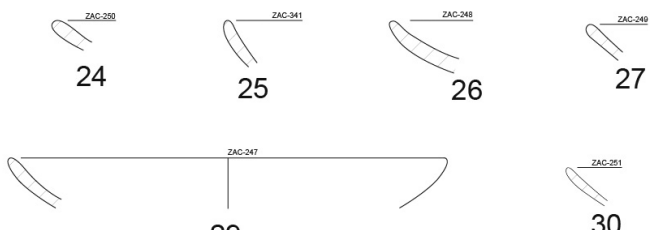

29

30

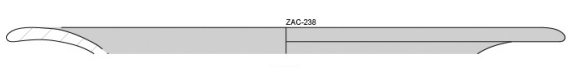

35
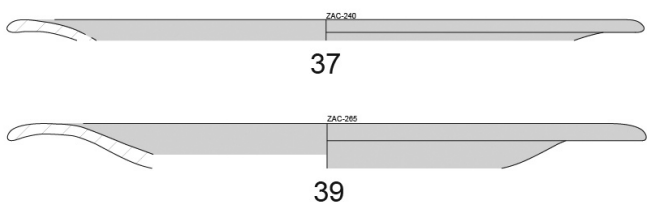
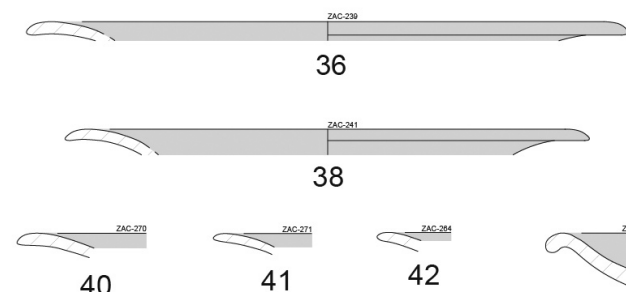

42

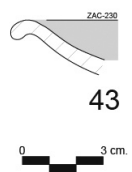

Figura 8. Platos. Común ibérica: COM-IB Pl0 (6, 10-15), COM-IB Pl10 (16), COM-IB Pl11 (17), COM-IB P112 (18), COM-IB P113 (19-21), COM-IB P114 (22-24), COM-IB P115 (25-31), COM-IB P131 (32-33). Barniz rojo indígena: BRI Pl0 (1-5,7-9), BRI P131 (34-42), BRI Pl32 (43). 


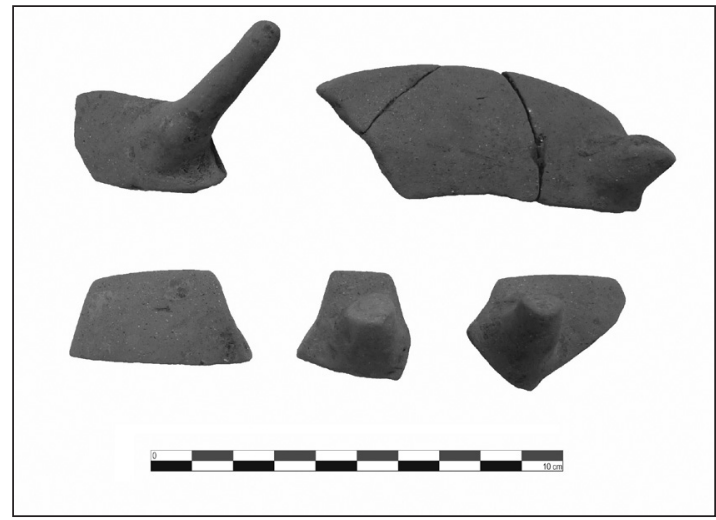

Figura 9. Copa en cerámica común imitando formas griegas (ZAC-244) (fotos: autores).

5,1 y 3) que sin duda se trata de formas de época arcaica, quizás siglos VII-VI a.C. entre otras cosas no ya sólo por los perfiles del borde, constatados en esos niveles de Iliberri, sino también por la arcilla poco depurada, que no coincide con las arcillas que solemos encontrar en contextos de época pleno ibérica; por el lado contrario encontramos otras cuatro intrusiones que ya sea por los perfiles o por el extremado índice de erosión, parece poco probable que pertenezcan finalmente al depósito; es el caso de los números 287 , 290, 291 y 292, las cuales ni siquiera han podido ser dibujadas. Tras la eliminación de las intrusiones nos queda un reducido número de urnas (17 fragmentos, entre ellos doce bordes, dos fondos - EVE 0,65; e.b. $=1,10$; e.f. $=0,25-\mathrm{y}$ tres amorfos que pesan 196,5 gramos, en solo 13 lotes). Uno de los bordes de las urnas está relacionado con un kalathos de cuello estrangulado, que serían característicos de esta época (García Cano 1996), concretamente el núm. 260 (Fig. 6: 11), correspondiente con los tipos 8-A/B de Pereira (1988: 160).

Para terminar nos quedaría revisar la forma de vaso de perfil en $\mathrm{S}$ y borde divergente. Tenemos 7 fragmentos, repartidos en 4 bordes y 3 fondos, EVE 0,55 (e.b. $=0,30$; e.f. $=0,90$ ) con un peso total de 84,6 gramos en siete lotes. Los fondos unidos a los vasos nos están hablando de caliciformes más o menos desarrollados, a los que corresponden todos los elementos menos uno de ello, el número 245 (Fig. 6: 26), que posiblemente se trate de un vaso-tapadera, de borde divergente, muy alto, ligeramente engrosado al interior y con una ranura bajo el borde en la parte interna; este ejemplar podría relacionarse con el tipo 16-C-III de Pereira (1988: 169) que encaja plenamente en el siglo IV a.C.

Dentro de la familia de las producciones de carácter no indígena, y que, por tanto, deben ser consideradas materiales de importación, observamos que la totalidad de las piezas que podemos asociar pertenecen a la familia de las cerámicas de origen semita.

Por orden cronológico empezamos por las producciones más antiguas. Se trata de dos piezas que parecen corresponder a sendos fragmentos de pithoi

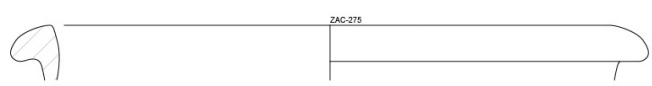

1
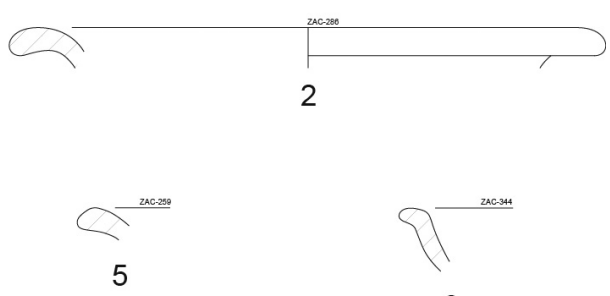

5

3
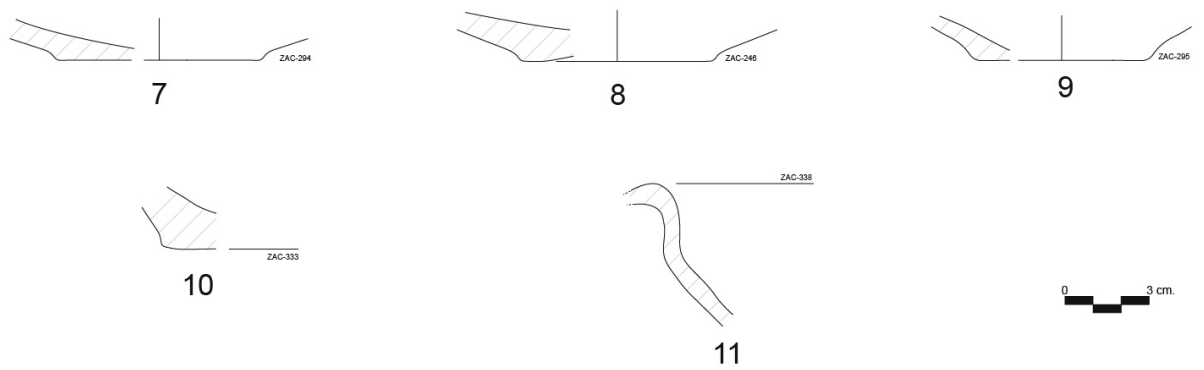

Figura 10. Intrusiones. Cerámica común ibérica: COM-IB Ur0 (1, 3-5), COM-IB Fu0 (2, 6-9), COM-IB Lb0 (11). Cerámica a mano: olla (10). 


\begin{tabular}{|c|c|c|c|c|c|c|}
\hline tipo & $\begin{array}{c}\text { Frag- } \\
\text { mentos }\end{array}$ & Bordes & Fondos & Peso & EVE & lotes \\
\hline $\begin{array}{c}\text { COM-IB } \\
\text { P111 }\end{array}$ & 4 & 4 & 0 & 51 & 0,18 & 1 \\
\hline $\begin{array}{c}\text { COM-IB } \\
\text { P112 }\end{array}$ & 1 & 1 & 0 & 2,7 & 0,25 & 1 \\
\hline $\begin{array}{c}\text { COM-IB } \\
\text { P113 }\end{array}$ & 6 & 6 & 0 & 96,4 & 0,28 & 3 \\
\hline $\begin{array}{c}\text { COM-IB } \\
\text { P114 }\end{array}$ & 4 & 4 & 0 & 11,2 & 0,10 & 3 \\
\hline $\begin{array}{c}\text { COM-IB } \\
\text { P115 }\end{array}$ & 8 & 8 & 0 & 42,5 & 0,24 & 7 \\
\hline $\begin{array}{c}\text { COM-IB } \\
\text { P131 }\end{array}$ & 2 & 2 & 0 & 17,5 & 0,05 & 2 \\
\hline
\end{tabular}

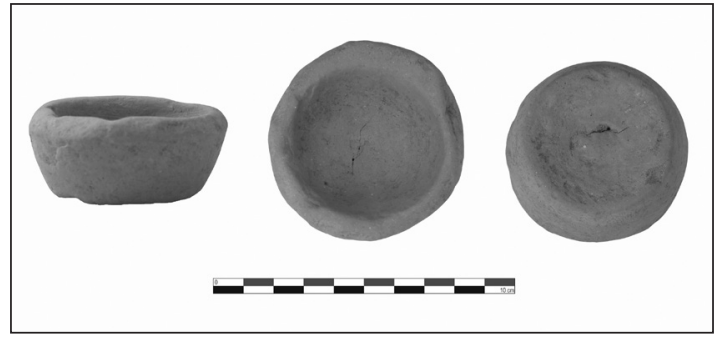

Figura 12. Ejemplar de un plato de pescado de tipo púnico, con pocito central, pero cuyo fondo ha sido recortado a modo de pieza discoidal, y que según la tipología de Federico Molina, corresponde a un COM-PUN P12 (ZAC-229) (foto: autores).

considerar que pudiera emular la funcionalidad (algo desconocida en general, también es cierto) de estas piezas, ya que se caracterizan por ser fragmentos planos, mientras que nuestro ejemplar (núm. 229) (Fig. 6: 34) presenta un volumen tridimensional importante, ya que compete a todo el pocito central del fondo del plato. En cuanto a la tipología, y tomando como base la desarrollada para la necrópolis de Puente de Noy en Almuñécar (Granada), a falta del labio podríamos incluirlo sea en el tipo II o en el tipo III, si bien, siguiendo a los autores (Molina Fajardo et alii 1982: 206), si tenemos en cuenta que el primero abarca la mitad inicial del siglo IV mientras que el segundo es más reciente (-350/-300) parece más que probable que el ejemplar del Zacatín se relacione con la más antigua, de modo que quedaría adscrito a la forma COM-P-H P12.

Dentro del ámbito de la cerámica común nos encontramos con una pieza hasta ahora no documentada en el interior, un pequeño jarrito de borde engrosado en banda al exterior, y un asa vertical que une la espalda al borde, de producción púnico centro-mediterránea, concretamente la forma COM-PUN 521 (Lancel 1987), la núm. 237 (Fig. 6: 33); presenta una arcilla porosa, aunque está muy alterada por el fuego, pues el color de la superficie es grisáceo oscuro a negro como consecuencia de la tensión térmica sufrida. Está fragmentada en cuatro piezas, tres de ellas correspondientes al borde. Esta pieza no es nada frecuente al interior peninsular, aunque se trata de uno de los jarritos cartagineses mejor conocidos en el conjunto del Mediterráneo occidental (Py et alii 2001: 1032, con abundantes atestaciones y referencias). En la necrópolis del Mirador de Rolando hay una pieza (Arribas Palau 1967: Fig. 14, 49) que es del todo ajena a las producciones indígenas ibéricas. Se trata de un pequeño jarro de un asa vertical con el labio engrosado al exterior a banda (Fig. 19: 1); el parecido con la forma COM-PUN 521 es tan importante, lo que nos lleva plantearnos que se trata ${ }^{16}$ Se puede paralelizar con el tipo 17-D de Pereira, presente
n Martos y en Baza; esta forma, sin duda, evoluciona de los platos de pescado púnicos de las costas andaluzas. 

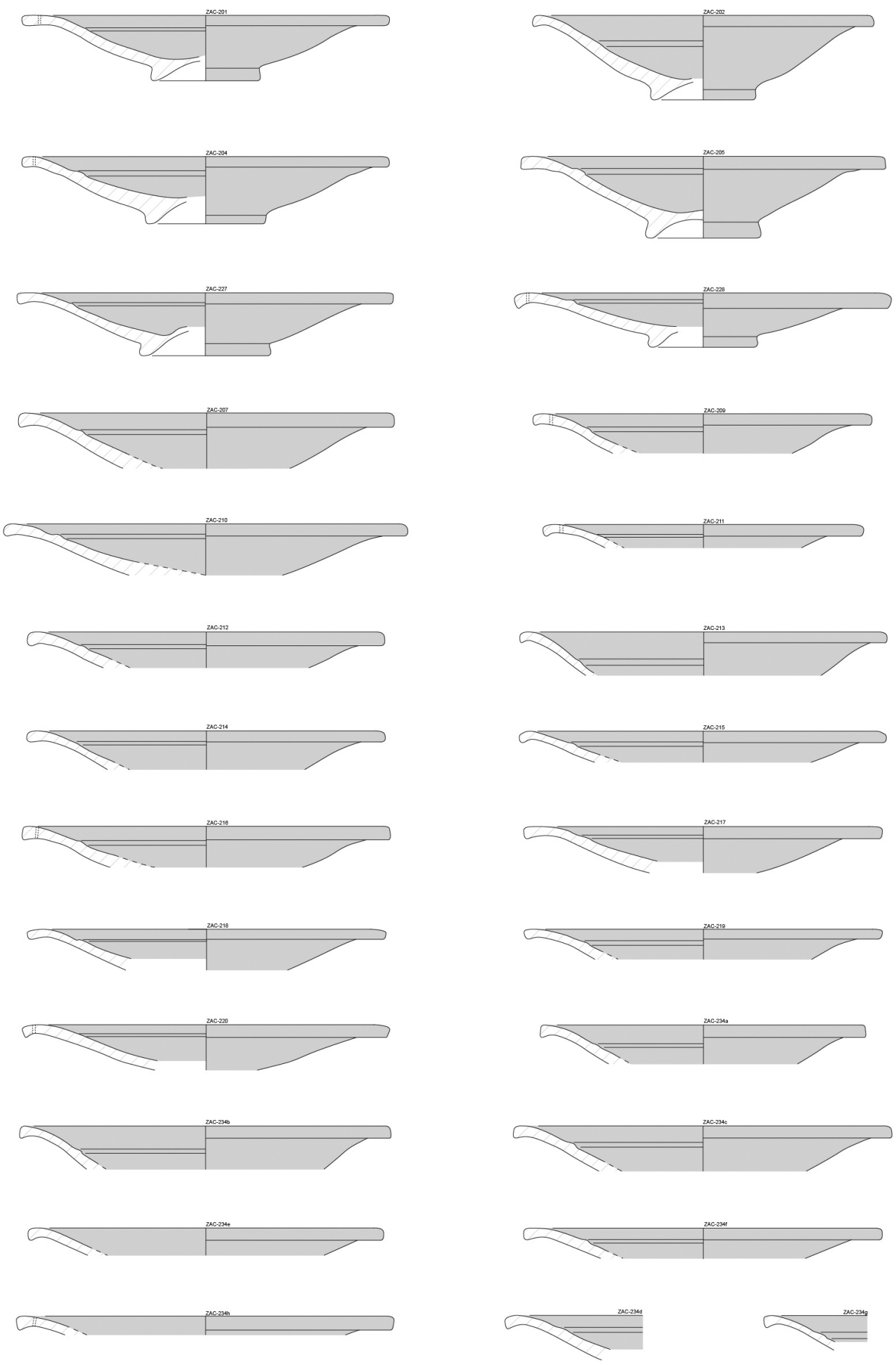

Figura 13. Platos de Barniz rojo indígena Pl34. 

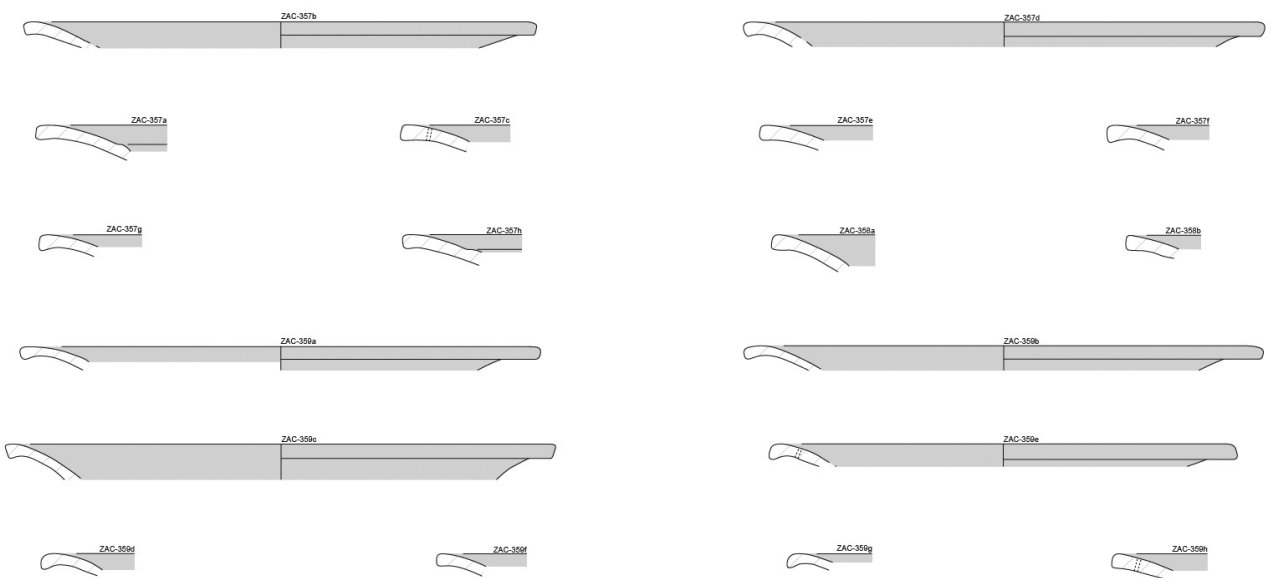

$$
\overbrace{}^{\text {2AC.SOEO }}
$$

$\overbrace{}^{\text {2ac-3500 }}$
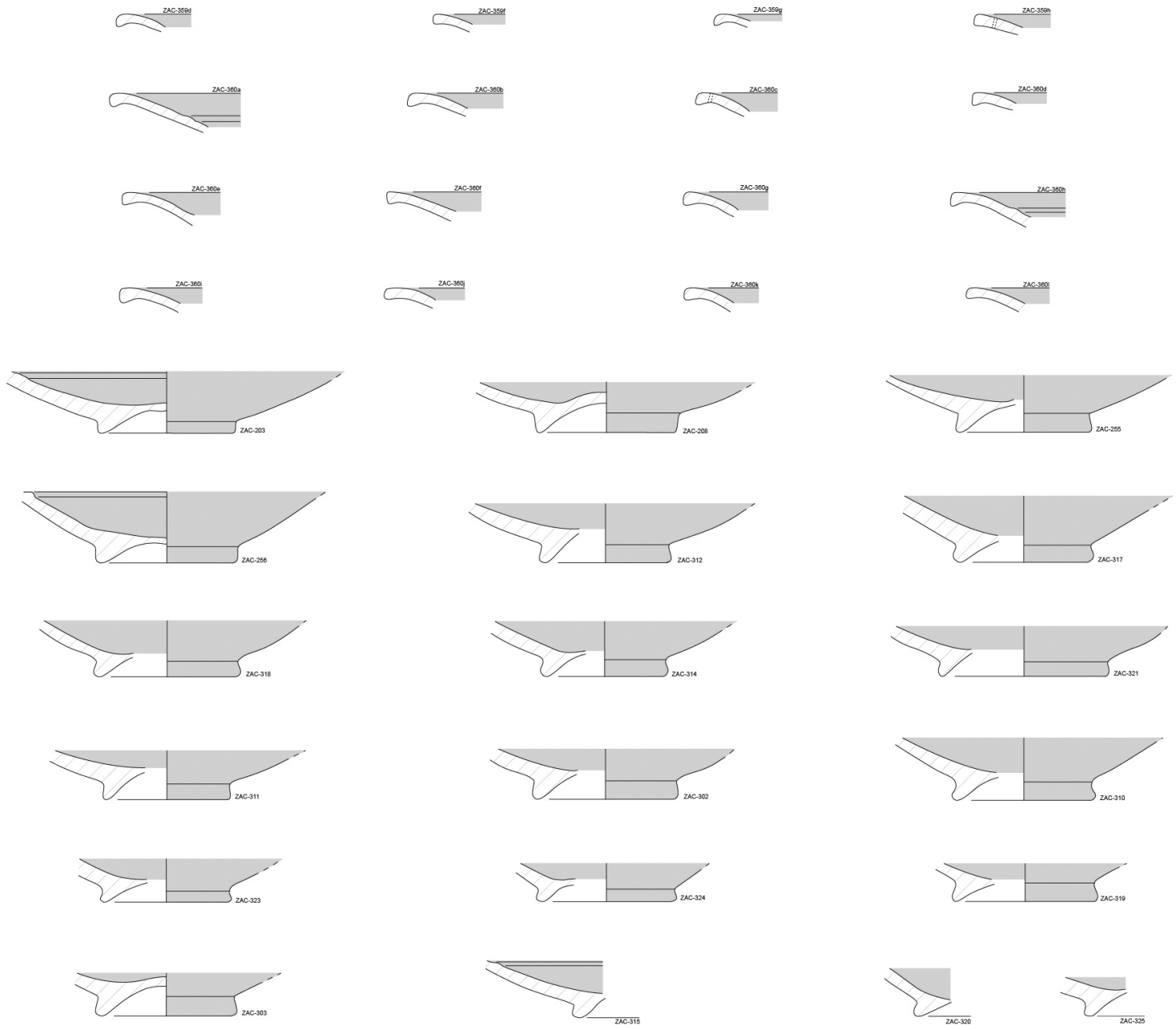

Figura 14. Platos de Barniz rojo indígena Pl34. 
de otro ejemplar de esta producción, casualmente en el mismo contexto cronológico y parecido contexto cultural, ya que se trataría de un espacio sacralizado (una tumba o quizás un silicernium) $)^{17}$. Existe una pieza que no hemos podido analizar personalmente procedente de la necrópolis del Mirador de Rolando (Granada), y que se corresponde con el tipo 9-D de Pereira (1988: 162), que para algunos se trata de una evolución de los lekythos aryballisticos griegos; desde nuestro punto de vista es más que probable que se trate de otra pieza de origen centro-mediterráneo, que pueden aparecer pintadas; el parecido formal con la que aquí presentamos es innegable, por lo que insistimos en la posibilidad de que ambas sean de origen púnico centromediterráneo.

\subsection{Protohistórica Fina}

En esta categoría entraría solamente dos clases cerámicas; la cerámica pintada ibérica y el barniz rojo indígena.

La cerámica pintada ibérica es extraordinariamente poco frecuente en el conjunto del Zacatín. Apenas contamos con cinco bordes y ningún fondo (EVE $0,17$; e.b. $=0,35)$ con un peso de 60,5 gramos y repartidos en 4 lotes. Además, de ellos el núm. 292 es una pequeña urna muy erosionada, con restos de pintura en el labio; presenta algo de cuello y un labio curvo horizontal, más característico de producciones tardoibéricas, lo que nos lleva a pensar que se trata de un elemento intrusivo en este conjunto. Tampoco queda claro que forme parte del conjunto la pieza núm. 233 (Fig. 6: 1), pues presenta una ranura en el plano de reposo del borde, a modo de asiento de tapadera lo que no es nada frecuente en las urnas ibéricas meridionales, salvo en época tardía; la pintura roja se observa en el cuello y en el hombro, sin que pueda diferenciarse bandas ni filetes; es probable que se trate de una zona con pintura en toda su superficie, menos el borde. De modo que si eliminamos estos dos lotes, nos quedamos con 3 fragmentos de bordes (con un EVE de 0,10, muy bajo; e.b. =0,20), dos de ellos pertenecientes a un kalathos de cuello estrangulado (núm. 258) (Fig. 6: 2) con un diámetro de boca de $17 \mathrm{~cm}$, que casaría muy bien con la cronología del conjunto. El otro borde se corresponde con otra urna de cuello corto y labio vertical engrosado; aparecen restos de engobe en el labio. Por su parte la arcilla, algo más rojiza que la mayor parte de los

\footnotetext{
${ }^{17}$ Con todo es notable la relación, especialmente visible desde un punto de vista tipológico, con los lekythos aryballísticos de producción ática
}

materiales de producción local, es igualmente más compacta, lo que nos hace sospechar que el material es de proveniencia externa, aunque siempre dentro de las producciones ibéricas.

Para terminar, nos queda hablar del barniz rojo indígena ${ }^{18}$; se trata de un grupo relativamente grande, compuesto por 490 fragmentos, con 274 bordes (e.b. $=18,52), 56$ fondos (e.f. = 15,80), $($ EVE 17,17) 160 amorfos, pesando un total de $3.415,3$ gramos repartidos en 75 lotes. Históricamente se ha considerado que esta clase cerámica es heredera de los barnices rojos de tradición semita característicos de las producciones occidentales desde los inicios de la colonización fenicia hasta bien entrado el siglo v a.C.; a partir de la primera mitad del siglo vi a.C. el barniz rojo parece centrarse en formas abiertas, quizás como consecuencia de la evolución que se observa en la tendencia de la desaparición de las formas cerradas con engobe formando parte de los ajuares funerarios de ámbito colonial.

En los contextos del Sureste peninsular y de la Alta Andalucía los engobes rojos indígenas son más propios de cronologías algo más tardías, particularmente del siglo III a.C.; por esto tiene particular interés la presencia de este grupo en un contexto cerrado y bien datado con un siglo de anterioridad.

De hecho, esta clase cerámica es sin duda la más frecuente del conjunto que presentamos en este trabajo, puesto que representa solo el 33,33\% de los fragmentos o el 15,50\% de los amorfos, así como el $30,13 \%$ del peso total (variables todas ellas dependientes de la potencial pérdida de barniz de muchos de ellos, especialmente los amorfos, como ya comentamos más arriba), pero cuando analizamos variables que asocian fragmentos diagnóstico los porcentajes se invierten respecto al resto de los grupos; por ejemplo, el 77,62 \% de los bordes, el 69,14 de los fondos (EVE $70,63$; e.b. $=75,10$; e.f. $=66,16)$; y eso solamente en el $45,18 \%$ de lotes, lo que significa que el índice de agrupación de fragmentos en vasos es superior a la media de este conjunto.

Desde un punto de vista tipológico, en el conjunto de la clase de engobes rojos, todas las formas son abiertas, concretamente platos, si bien distribuidos en tres formas; un solo ejemplar se asocia a BRI P132 (plato de borde vuelto grueso, de tradición antigua), el núm. 230 (Fig. 8: 43), y que podría tratarse de una pieza intrusiva, ya que presenta una arcilla muy poco depurada, característica propia de las producciones

\footnotetext{
${ }^{18}$ En este caso apostamos por el concepto de barniz rojo en vez de engobe rojo por la fuerte tradición historiográfica que presenta el primer término a pesar de su evidente escasa fiabilidad terminológica-descriptiva.
} 
ibérico-antiguas. Se trata además de un solo fragmento y muy pequeño, no ha podido ser medido su diámetro de borde y apenas pesa 12 gramos. El grupo de platos de borde vuelto simple BRI Pl31 (Fig. 8: 34-42) es más numeroso, compuesto por 9 lotes, 14 fragmentos que incluyen 14 bordes $($ EVE 0,38; e.b. $=0,77)$ y pesan un total de 138,8 gramos. Estos platos perdurarán en momentos más tardíos (siglo III a.C.), y posiblemente sean consecuencia de la evolución del plato de engobe rojo de borde vuelto fenicio, habiendo perdido la marcada diferencia entre el cuerpo y el borde que caracterizaba a las producciones semitas, y convirtiéndose en una forma de perfil continuo al interior.

Mucho mejor representado es el plato BRI P134 (Fig. 13 y 14). Sin duda el tipo más numeroso y repetitivo de todos los presentados en este trabajo, y, el segundo de todo el depósito (sólo superado por las kylix de resalte interno de figuras rojas áticas). Tenemos un total de 445 fragmentos que pesan 2969 gramos, y se reparten entre 259 bordes, 39 fondos (EVE 15,15; e.b. $=17,70$; e.f. $=12,60)$ y 147 amorfos, ubicados en 53 lotes.

Tipológicamente es difícilmente clasificable; se trata de un plato de ala, inscrito en la tradición plenamente semita de los antiguos platos de engobe rojo de época arcaizante, pues podría relacionarse con el tipo VIIc de Negueruela (1979-1980), o quizás con los platos de Huelva de la fase Tartésica final III, pero que se data a mediados del siglo vi a.C. (Rufete Tomico 1988-1989), ni siquiera en yacimientos del interior podríamos bajar de finales del siglo vi a.C. como en la fase IV de Montemolín (Macebo Dávalos 1991-1992); el borde está separado del galbo interno por una arista o resalte en forma de bocel; el labio al exterior es recto, con un gesto que elimina el remate curvo de éste tan propio de las producciones arcaizantes a las que mencionábamos anteriormente. El perfil en general es suave, continuo, produciendo un plato de escasa capacidad, más propio de una forma para presentar o para alimentos sólidos que para líquidos; el fondo interno presenta un ligero abombamiento convexo, lo cual, unido a un fondo externo excavado, hace que la sección de la pared sea muy estrecha, de modo que se convierte en una de las zonas más débiles estructuralmente de la pieza. Está completamente barnizado de rojo, aunque en nuestro caso el barniz en muchos casos ha desaparecido casi por completo. Otra característica no tipológica es la presencia, muy constante, en el labio de dos agujeros de suspensión realizados antes de la cocción (Fig. 15).

Lo extraño no es sólo que no hayamos encontrado paralelos a esta pieza en otros sitios, por el momento, si no que ni siquiera en niveles coetáneos de Iliberri existen paralelos confirmados. Solamente tenemos

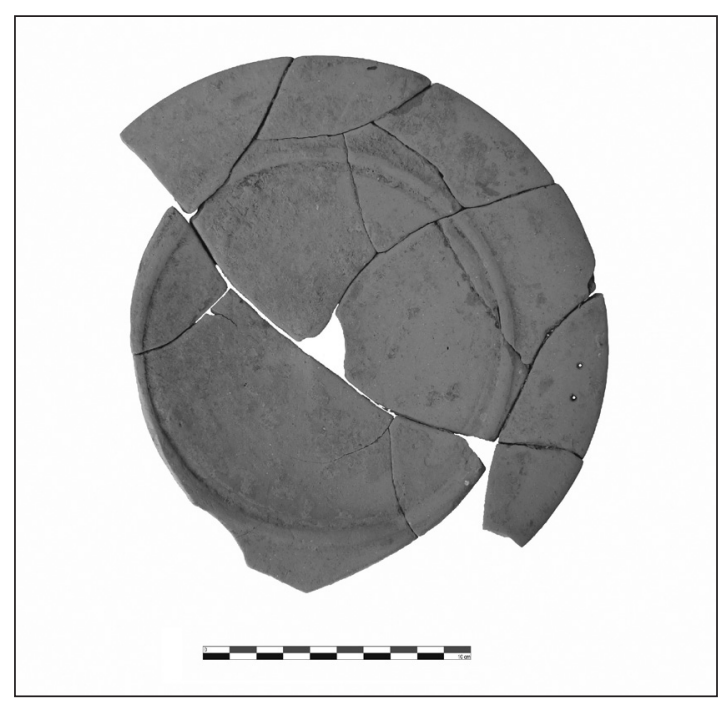

Figura 15. Imagen de un plato BRI P134. En él se pueden observar los orificios de suspensión, realizados antes de la cocción, que presentan muchos de estos platos (ZAC-204) (foto: autores).

dos excepciones; la primera no es segura ya que se trata de una reinterpretación del perfil de un plato de la necrópolis de Mirador de Rolando (Fig. 19: 2) que podría relacionarse con este tipo (Arribas Palau 1967: Fig. 14: 57) aunque en la descripción no se menciona la existencia de barniz ni otro tratamiento en la superficie de dicho vaso.

El otro caso es bastante más evidente. Se trata de cuatro platos localizados en un depósito de la calle San Antón, que ya mencionamos anteriormente. Aunque no están publicados como tal, una consulta a CERES, nos permite acercarnos a una serie de datos respecto a esta tipología (números CE11250, CE1 1920 (Fig. 20: 1), CE11921, CE11922). Se trata de un plato "de cuerpo troncocónico invertido muy abierto que continúa con un labio redondeado exvasado. Pie en anillo. El fondo de la cara externa tiene umbo y hacia la mitad del cuerpo tiene como decoración una acanaladura circular"; la altura se sitúa entre los 4,00 y $\operatorname{los} 4,40 \mathrm{~cm}$, el diámetro ronda los $19 \mathrm{~cm}$ y el diámetro de base se sitúa entre los 5,30 y los $5,50 \mathrm{~cm}$. En nuestro caso son algo más bajos (rondan los 3,5 $\mathrm{cm}$ ), y de pie más pequeño (los de Zacatín se sitúan en torno a los 5,8 cm) pero coinciden en anchura de borde $(19 \mathrm{~cm})$.

En cuanto al tratamiento de superficie, en San Antón no se menciona la presencia de engobe ni de barniz, lo que permite considerar que estos platos no estaban decorados de ninguna manera. Lo más curioso es la datación de este conjunto, que se sitúa en torno al año 100 a.C., por tanto, dos siglos y medio más 
reciente que el conjunto del Zacatín, y a pesar del tiempo transcurrido, y a excepción del engobe, las características morfológicas y morfométricas son muy semejantes; un claro caso de inmovilismo tecnológico.

\section{DISCUSIÓN}

Hay dos enfoques en la discusión sobre este conjunto que presentamos; el primero de ellos está en relación a aspectos cronológicos y el segundo en relación a aspectos funcionales.

El conjunto que aquí presentamos parece remitirnos a época plena del desarrollo del mundo ibérico, aunque contamos con una serie de problemas serios para establecer los parámetros adecuados que nos permitan cerrar la cronología a partir de los materiales indígenas.

En este sentido debemos decir que uno de los principales problemas historiográficos con que seguimos topando en la arqueología ibérica del ámbito de la Alta Andalucía es la carencia de publicaciones adecuadas respeto a conjuntos estratigráficos bien documentados. La protohistoria de la zona mediterránea francesa ha demostrado con sus trabajos que debemos superar la fase de cronologías a partir de fósiles guías para empezar a datar por conjuntos bien contextualizados, ya que en ocasiones los materiales de importación pueden perjudicar la visión cronológica de un conjunto ya que éstos tienden a amortizarse más que los materiales indígenas.

En el caso de la provincia de Granada las numerosas excavaciones de urgencia que se han venido produciendo en los últimos años apenas han tenido repercusión científica ya que no se han publicado con las garantías suficientes para realizar aportaciones al conocimiento, demostrando el fracaso del modelo de gestión de patrimonio arqueológico realizado desde esta perspectiva; los escasos datos con que contamos que parecen contemporáneos a nuestro contexto estarían formados por dos casos como la necrópolis de Mirador de Rolando, aunque no se recuperaron todos los materiales (Arribas Palau 1967), y, más recientemente, las excavaciones de Loma Linda en Ogíjares (Rodríguez Ariza 1991-1992). Ya hemos mencionado anteriormente la relación con los perfiles de los bordes de las ánforas; igualmente podemos ver que otras formas están presentes en Loma Linda, como los kalathos de cuello estrangulado (Rodríguez Ariza 1991-1992: 12, h), los vasos caliciformes (Fig. 12, g) o algunos platos, de perfil curvo (Fig. 15, e), carenado en el tercio superior (Fig. 14, a) o incluso los de borde vuelto (Fig. 14, d). No obstante encontramos un paralelo para una pieza que difícilmente podemos reconstruir, una especie de jarro de labios gruesos, divergentes y rectos, nuestro núm. 337, semejante a una forma representada en Loma Linda (Fig. 12, f) pero que, al igual que el ejemplar del Zacatín, sólo presenta el borde, sin que conozcamos el desarrollo del cuerpo. Bien, pues el material de este yacimiento, al parecer monofásico, nos lleva al siglo IV o inicios del siglo III a.C., por lo que podemos comprobar que existe ciertas concomitancias entre ambos conjuntos, a excepción, una vez más, del plato BRI P134, que tampoco está presente en Loma Linda.

Sí que nos gustaría resaltar respecto a las cronologías las relaciones con otros dos conjunto bien datados. El primero de ellos en relación al comportamiento de los platos. Se trata de los hornos de Cerro Macareno en Sevilla en los cortes H.I y H.II, datados entre mediados del siglo $\mathrm{V}$ y primer cuarto del siglo IV a.C. (Ruiz Mata y Córdoba Alonso 1999), donde, según los autores se trata del grupo más numeroso representado en estos contextos, caracterizándose por bordes indiferenciados y terminaciones redondeadas o apuntadas; al observar los perfiles de la Fig. 7 de la publicación uno comprueba que la mayor parte de ellos presentan un grosor continuo en el perfil, y efectivamente son rectos y divergentes, salvo algún caso concreto. Si comparamos lo que sucede en los llamados santuarios bastetanos (Adroher Auroux y Caballero Cobos 2008) que frecuentemente son más recientes (a partir del siglo IV a.C., y con gran cantidad de platos) éstos presentan un perfil más estrecho, siempre de labios apuntados, y, conforme nos acercamos al cambio de Era, son más frecuentes los carenados en el tercio superior (COM-IB P114), uno de los menos frecuentes en el Zacatín. Este fenómeno, unido al rebaje de los bordes de las ánforas lo podemos ver en Fuente Amarga, poblado fortificado datado entre los siglos III y II a.C., (Rodríguez Ariza et alii 1999, 290, g; 291, a).

Ciertamente podemos comprobar que el material indígena puede, en consecuencia, aproximar cronologías sin necesidad de establecer protocolos de fósiles guía, aún a falta de suficientes estratigrafías.

El segundo punto donde queremos profundizar es establecer una interpretación más precisa de este material en su contexto.

Tras las diversas discusiones que hemos establecido en torno a los problemas de materiales intrusivos por la ubicación del depósito junto al río, empezaremos por una propuesta concreta del material que exactamente consideramos que forma parte del mismo, dejando por completo de lado los fragmentos considerados exógenos por las razones que se han ido esgrimiendo a lo largo de nuestro discurso. 


\begin{tabular}{|l|c|c|c|c|c|c|c|c|}
\hline selección & \multicolumn{1}{c}{ á-ibér } & \multicolumn{1}{c}{ á-pún } & \multicolumn{1}{c}{ b-rojo } & \multicolumn{1}{c}{ cocina } & \multicolumn{1}{c}{ común } & com-pún & pintada & pún-his \\
\hline fragmentos & 36 & 1 & 490 & 63 & 852 & 3 & 4 & 1 \\
\hline bordes & 3 & 1 & 274 & 0 & 55 & 3 & 4 & 0 \\
\hline asas & 1 & 0 & 0 & 0 & 2 & 0 & 0 & 0 \\
\hline fondos & 0 & 0 & 56 & 0 & 19 & 0 & 0 & 1 \\
\hline amorfos & 32 & 0 & 160 & 63 & 776 & 1 & 0 & 0 \\
\hline est. bordes & 0,58 & 0,05 & 18,52 & 0 & 4,01 & 0,50 & 0,30 & 0 \\
\hline est. fondos & 0 & 0 & 15,80 & 0 & 5,68 & 0 & 0 & 1,00 \\
\hline peso & $1.670,9$ & 17,7 & $3.415,3$ & 686 & $5.028,9$ & 32 & 55,3 & 69 \\
\hline
\end{tabular}

Figura 16. Tabla en la que se puede observar el reparto de valores por clases cerámicas.

En fin, de los fragmentos presentados pertenecen realmente al depósito 1451 de ellos, repartidos en 340 bordes (e.b. $=23,96), 3$ asas, 76 fondos (e.f. $=22,48$ ) y 1.032 amorfos, con un peso de 10.975 gramos y EVE de 23,22 (Fig. 16).

Si nos remitimos a la cuantificación por EVE vemos la notable diferencia en la representatividad de las diferentes clases; como comprobamos en la tabla siguiente (Fig. 17) los platos de barniz rojo son absolutamente mayoritarios, pues al menos contamos con 16 ejemplares, seguido de la cerámica común ibérica, con la que contamos con 6 piezas, y finalmente tenemos una pieza al menos en el resto de los $\operatorname{casos}^{19}$.

Para intentar aproximarnos al ajuar utilizado en el ritual, hemos optado por elevar al mínimo posible la clase peor representada (cocina ibérica), de modo que observaremos las diferencias en la representatividad de las diversas clases cerámicas (Fig. 17).

Con el objetivo de hacernos una idea de esta representatividad en el conjunto, al menos desde un punto de vista de relatividad (cuántos vasos por cada clase), elevamos el valor más bajo, el del ánfora púnica (así como el de la cerámica de cocina) a la unidad y, aplicando una regla de tres, obtenemos un servicio teórico de uso en este depósito. Este gráfico (Fig. 18) nos indica el material presente por cada ánfora púnica a nivel teórico; podemos comprobar que el material más importante es, sin duda, el barniz rojo indígena, dentro del cual el plato BRI Pl34 representa un elemento esencial.

Si bien en el presente trabajo nos hemos centrado en los materiales cerámicos ibéricos y púnicos, el conjunto es importante por su homogeneidad; en realidad tenemos platos y vasos para beber, con algunas urnas y escasas ánforas. Sin duda este depósito nada

\footnotetext{
${ }^{19}$ Se trata de valores absolutos, ya que los EVE en ningún caso a lo largo del discurso se han valorado porcentualmente salvo que se haya especificado lo contrario.
}

tiene que ver con ámbitos funerarios, ya que faltan los elementos característicos de los ajuares funerarios; desde nuestro punto de vista se trata de una ofrenda a la divinidad fluvial que se significa en el río Darro. En ese sentido nos gustaría apuntar algunas reflexiones en torno al depósito de San Antón sobre el cual poco se ha escrito. Dicho depósito, a juzgar por los materiales presentes en CERES, se compone de cuatro cubiletes de paredes finas (números CE11928, CE11929, CE11930 y CE11931 (Fig. 20: 4), tres anforiscos (números CE11245, CE11916 (Fig. 20: 2) y CE11918), dos caliciformes (números CE11926 (Fig. 20: 5) y CE11927), y siete platos repartidos entre P111 (dos ejemplares, números CE11247 (Fig. 20: 3) y CE11249), un P114 (número CE11923) (Fig. 20: 6) y cuatro Pl34 (números CE11250, CE11920 (Fig. 20: 1), CE11921 y CE11922); en definitiva contamos con seis vasos para beber (cubiletes y caliciformes) siete platos y tres anforiscos. Podría decirse que el ajuar estaría compuesto por una ratio de un plato para comer o presentar, un vaso para beber y el transporte de la ofrenda líquida que se realizaría en los anfo-

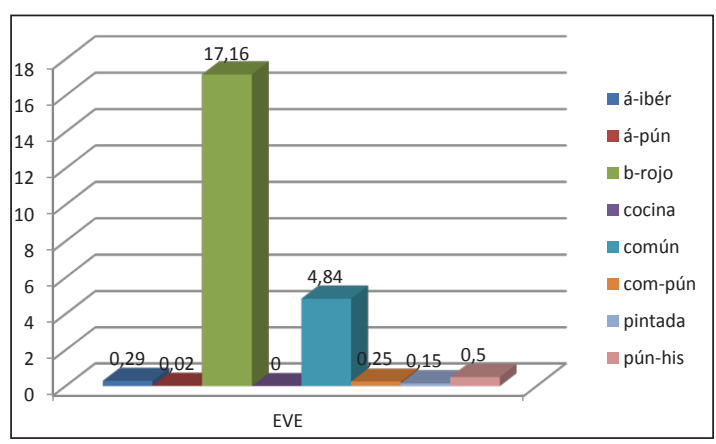

Figura 17. Cuadro en el que en base a la cuantificación por EVE (según bordes), podemos ver la notable diferencia en la representatividad de las diferentes clases. 


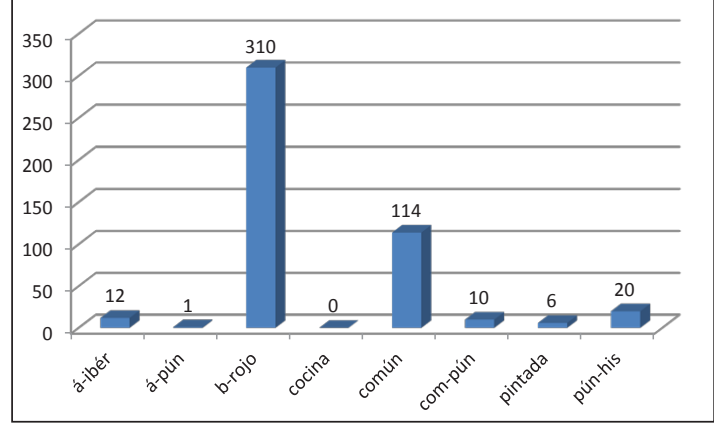

Figura 18. Cuadro en el que podemos observar el material presente por cada ánfora púnica a nivel teórico.

riscos, de modo que cada uno de éstos daría juego a dos servicios de plato/vaso.

En el caso de San Antón, la mayor parte de las formas localizadas están en relación con el consumo de algún producto líquido (copas para beber) y quizás algún producto semilíquido o sólido (garum o algún elemento cocinado), lo que lo relaciona muy directamente con lo que tenemos presente en el depósito de Zacatín; en el primer caso no hay urna, y en el segundo están escasamente representadas (la estimación de borde de urnas arroja un valor de 1,10, mientras que el de bordes de platos es de 19,85, lo que nos proporcionada una ratio de 17,14 platos por cada urna).

Tanto en San Antón como en Zacatín el plato Pl34 es la pieza mayoritaria entre los materiales indígenas, incluso en el primer caso es la pieza mayoritaria de todo el depósito (25\% en número del total de piezas), mientras que en el segundo caso está por debajo de las kylix de figuras rojas ática (a pesar de lo cual representa el 13,58 \% del EVE total del Zacatín). Sin embargo, dicho tipo no ha sido localizado con seguridad fuera de este grupo de depósitos asociados al río Darro, lo cual nos invita a plantearnos la opción
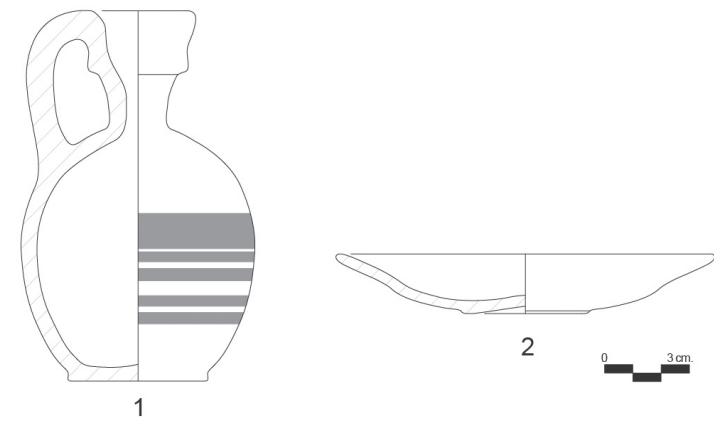

Figura 19. Pequeño jarrito con asa y plato procedentes de la necrópolis de Mirador Rolando (elaboración propia a partir de Arribas Palau 1967).

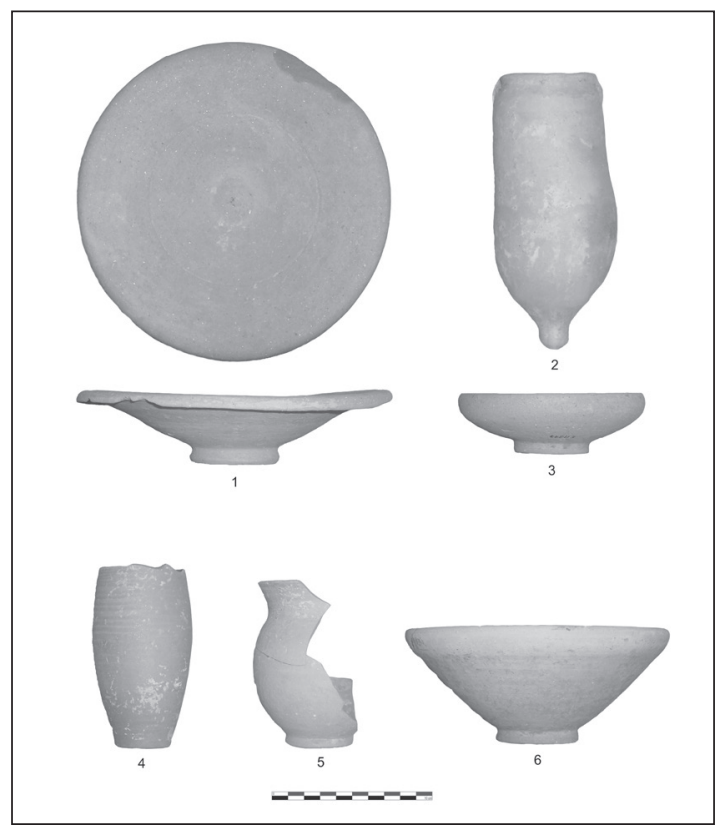

Figura 20. Muestra tipológica de la cerámica documentada en el depósito de San Antón. Cerámica común ibérica: COM-IB Pl34 (1) (CE11920), COM-IB anforisco (2) (CE11916), COMIB Pl11 (3) (CE11247), COM-IB Vs0 (5) (CE11926), COM-IB P114 (6). Cerámica clásica: PAR-FIN (4) (CE11931) (elaboración propia a partir de http://ceres.mcu.es).

de que los platos Pl34, sea en producción de engobe sea en producción común, son ajuares indígenas que se fabrican en exclusiva para la realización de ciertos tipos de rituales votivos.

\section{BIBLIOGRAFÍA}

Adroher Auroux, A. M. 2013a: "El territorio ideológico en el área bastetana", C. Risquez y C. Rueda (eds.), Santuarios ibéricos: territorio, ritualidad y memoria, actas del Congreso sobre El Santuario de la Cueva de la Lobera, Castellar (Jaén), Jaén, 145-181.

Adroher Auroux, A. M. 2013b: "S.I.R.A. Reflexiones sobre la normalización en el estudio de cerámicas procedentes de excavaciones arqueológicas", $R e$ vista Cira Arqueológica 3, 404-424.

Adroher Auroux, A. M. y Caballero Cobos, A. 2008: "Los santuarios al aire libre en el entorno de Basti (Baza, Granada)", A. M. Adroher y J. Blánquez (eds.), 1er Congreso Internacional de Arqueología Ibérica Bastetana, 2, Serie Varia 9, Madrid, 215-227.

Adroher Auroux, A. M. y Caballero Cobos, A. 2012: "Santuarios y necrópolis fuera de las murallas: 
el espacio periurbano de los oppida bastetanos", M. C. Belarte y R. Plana (eds.), El paisatge periurbà a la Mediterrània occidental durant la protohistòria i l'antiguitat, Documenta 26, Tarragona, 231-244.

Adroher Auroux, A. M. y López Marcos, A. 2000: "Ánforas de tipo ibérico en las depresiones intrabéticas granadinas", Revista de Estudios Ibéricos 4, Madrid, 105-150.

Adroher Auroux, A. M. y López Marcos A. (ed.) 2001: Excavaciones arqueológicas en el Albaicín (Granada). I. El Callejón del Gallo, Granada.

Adroher Auroux, A. M., Caballero Cobos, A. y Barturen Barroso, F. J. 2001b: "Materiales. La cerámica”, A. M. Adroher y A. López (ed.), Excavaciones arqueológicas en el Albaicín (Granada). I. El Callejón del Gallo, Granada, 87-105.

Adroher Auroux, A. M., Sánchez Moreno, A. y Caballero Cobos, A. 2005: "El oppidum ibérico de Ilturir-Iliberri”, C. Vílchez et alii (coord.), Los vidrios griegos en Granada, Granada, 75-86.

Adroher Auroux, A. M., Risueño Olarte, B., López Marcos, A. y Pérez Rivera, J. M. 1995: "Excavación de urgencia en calle Espino, 5 (Albayzín, Granada), febrero-abril 1991", Anuario Arqueológico de Andalucía 1992/III, Sevilla, 319-328.

Adroher Auroux, A. M., López Marcos, A., Barturen Barroso, F. J., Salvador Oyonate, J. A. y Caballero Cobos, A. 2001: "Discusión", A. M. Adroher y A. López (eds.), Excavaciones arqueológicas en el Albaicín (Granada). I. El Callejón del Gallo, Granada, 183-214.

Alzola Romero, A. 2005-2006: “Adaptación y aplicación del sistema de cuantificación PIE-Slice, un método para el estudio estadístico de covarianza", Kalathos 24-25, 47-67.

Arcelin, P. y Truffeau-Libre, M. (dir.) 1998: La quantifications des céramiques. Conditions y protocole, Bibracte 2, Glux-en-Glenne.

Arribas Palau, A. 1967: "La necrópolis bastitana del Mirador de Rolando (Granada)", Pyrenae 3, 67 105.

Barturen Barroso, F. J. 2008: "Iliberri”, A. M. Adroher y J. Blánquez (ed.), ler Congreso Internacional de arqueología ibérica bastetana, Serie Varia 9, Madrid, 267-286.

Barturen Barroso, F. J. 2008: "Iliberri: problemática de un asentamiento protoibérico", en: A. M. Adroher y J. Blánquez (ed.), ler Congreso Internacional de Arqueología Ibérica Bastetana, 2, Serie Varia 9, Madrid, 131-154.

Blázquez Martínez, J. M., García-Gelabert Pérez, M. P. y López Pardo, F. 1985: Castulo V, Excavaciones Arqueológicas en España 140, Madrid.
Bonet Rosado, H. y Consuelo Mata Parreño, C. 2008: "Las cerámicas ibéricas. Estado de la cuestión", D. Bernal Casasola y A. Ribera i Lacomba (eds.), Cerámicas hispanorromanas. Un estado de la cuestión, Cádiz, 147-170.

Caballero Cobos, A. 2008: "Nuevos datos sobre la necrópolis ibérica del Mirador de Rolando: excavación en la Calle Turia (Granada)", A. M. Adroher y J. Blánquez (eds.), ler Congreso Internacional de arqueología ibérica bastetana, Serie Varia 9, vol. 2, Madrid, 155-162.

Carreras Montfort, C. 2000: Economía de la Britannia romana: la importación de alimentos, Barcelona.

Carretero Poblete, P. A. 2007: "Agricultura y comercio púnico-turdetano en el Bajo Guadalquivir. El inicio de las explotaciones oleícolas peninsulares (siglos V-II)", BAR Int. Series 1703, Oxford.

Casado Millán, P., Pérez Barea, C., Orfila Pons, M., Moreno Onorato, A., Hoces Prieto, A. J., Pérez de Baldomero, F., Moreno Quero, M. y Liébana Sánchez, M. 1998: "Nuevos aportes para el conocimiento del asentamiento ibérico de Iliberri (Granada)", C. Aranegui (ed.), Actas del Congreso Internacional Los Iberos Príncipes de Occidente. Estructuras de poder en la sociedad ibérica, Saguntum, Extra 1, Valencia, 137-146.

Casado Millán, P. y Orfila Pons, M. 2011: "Los inicios de la ciudad de Granada: la Edad del Bronce y la época ibérica", M. Orfila Pons (ed.), Granada en época romana: Florentia Iliberritana, Granada, 25-39.

El Amrani Paaza, T. 2005: "Apuntes para una clasificación de los vidrios de núcleo de arena del Museo Arqueológico y Etnológico de Granada", C. Vílchez et alii (coord.), Los vidrios griegos en Granada, Granada, 107-121.

Florido Navarro, C. 1984: "Ánforas prerromanas sudibéricas", Habis 15, 419-436.

Gailledrat, E. y Rouillard, P. 2000: "Le mobilier", A. Badie et alii: Le site antique de La Picola (Alicante, Espagne), Paris-Madrid, 145-220.

García Cano, J. M. 1996: "Los Kalathoi de cuello estrangulado de las necrópolis ibéricas de Coímbra del Barranco Ancho (Jumilla, Murcia)", Anales de Arqueología Cordobesa 7, 33-44.

González Román, C., Adroher Auroux, A. M. y López Marcos, A. 1995: "El yacimiento de Canto Tortoso (Gorafe, Granada): un enclave comercial del siglo VI a.C. en el Guadiana Menor", Verdolay 7, 159-176.

Guerrero Ayuso, V. y Quintana, C. 2000: “Comercio y difusión de las ánforas ibéricas en Baleares", Quaderns de prehistoria i arqueologia castellonencs 21, 153-182. 
Horejs, B., Jung, R. y Pavúk, P. (ed.) 2010: Analysing Pottery: Processing, Classification, Publication, Studia Archaeologica et Medievalia 10, Bratislava.

Lancel, S. 1987: "La céramique punique d'époque hellénistique”, P. Lévêque y J.-P. Morel (ed.), Céramiques hellénistiques et romaines, II. Annales liitéraires de l'Université de Besançon 331, Besançon, 99-138.

López Castro, J. L., Martínez Hahnmüller, V., Moya Cobos, L. y Pardo Barrionuevo, C. 2011: "Excavaciones arqueológicas en Villaricos. La excavación de urgencia de 1987”, Baria 1, Almería.

López López, M. (ed.) 2001: Excavaciones arqueológicas en el Albaicín (Granada). II. Plaza de Santa Isabel la Real, Granada.

Lozano Rodríguez, J. A., Gámez-Leyva Hernández, M. L., Ruiz Puertas, G. y Hódar Correa, M. 2008: "Denominación, edad y funcionalidad del depósito de agua hallado entre las calles Álamo del Marqués y San José (Albaicín, Granada)", A.M. Adroher y J. Blánquez (eds.), ler Congreso Internacional de arqueología ibérica bastetana, 2, Serie Varia 9, Madrid, 117-130.

Macebo Dávalos, J. 1991-1992: "La cerámica de barniz o engobe rojo de Montemolín (Sevilla)", Zephyrus 44-45, 269-299.

Martín López, E., Rodríguez Aguilera, A. y Bordes García, S. 2004: "Informe-memoria científica de la intervención arqueológica de urgencia Carril de las Tomasas no 4 (Albaicín, Granada)", Anuario Arqueológico de Andalucía 2001/III-1, Sevilla, 363-370.

Martínez Fernández, V. M. 2012: “Teoría del discurso y paradigmas arqueológicos", Complutum 23, 51-68.

Martínez Hahnmüller, V. 2012: “La conquista romana de Baria”, Baria 2, Almería.

Mata Parreño, C. y Bonet Rosado, H. 1992: "La cerámica ibérica: ensayo de tipología", Serie de Trabajos varios del S.I.P. 89, Valencia, 117-174.

Molina Fajardo, F., Ruiz Fernández, A. y Huertas Jiménez, C. 1982: Almuñécar en la antigüedad. La necrópolis fenicio-púnica de Puente de Noy, Granada.

Molina Vidal, J. 1997: La dinámica comercial romana entre Italia e Hispania Citerior, Alicante.

Morillo Cerdán, A. y Adroher Auroux, A. M. 2013: "El patrón arqueológico de carácter material: un criterio imprescindible de identificación de recintos militares romano-republicanos", Revista Cira Arqueológica 3, 25-43

Negueruela Martínez, I. 1979-1980: "Sobre la cerámica de engobe rojo en España", Habis 10-11, 335-359.
Orfila Pons, M. (ed.) 2008: Granada en época romana: Florentia Iliberritana, Granada.

Orfila Pons, M. 2011: Florentia Iliberritana. La ciudad de Granada en época romana, Granada.

Orton, C. 1993: "How many pots make five?", Archaeometry 35 (2), 169-184.

Orton, C. y Tyers, P. 1993: A user guide to pie-slice, London.

Pachón Romero, J. A. 1997-1999: "El depósito de cerámicas griegas de la Calle Zacatín", Boletín de la Real Academia de Bellas Artes de Nuestra Señora de las Angustias 6-7, 189-194.

Pastor Muñoz, M. y Pachón Romero, J. A. 1991: “Informe de la prospección con sondeos estratigráficos en el Mirador de Rolando (Granada)", Florentia Iliberritana 2, Granada, 377-400.

Pastor Muñoz, M. y Pachón Romero, J. A. 1992: “Informe de la prospección con sondeos estratigráficos en el Mirador de Rolando (Granada)", Anuario Arqueológico de Andalucía 1990/III, 130-137.

Pellicer Catalán, M. 1978: “Tipología y cronología de las ánforas prerromanas del Guadalquivir según el Cerro Macareno (Sevilla)", Habis 9, 365-400.

Pellicer Catalán, M., Escacena Carrasco, J. L. y Bendala Galán, M. 1983: "El Cerro Macareno", Excavaciones Arqueológicas en España, 124, Madrid.

Pereira Sieso, J. 1988: "La cerámica ibérica de la cuenca del Guadalquivir. I. Propuesta de clasificación", Trabajos de Prehistoria 45, 143-173.

Piques, G. 2001: "Ictiofauna", A. M. Adroher Auroux y A. López Marcos (eds.), Excavaciones arqueológicas en el Albaicín (Granada). I. El Callejón del Gallo, Granada, 169-174.

Presedo Velo, F. 1982: "La necrópolis de Baza", Excavaciones Arqueológicas en España, 119, Madrid.

Py, M., Adroher Auroux, A. M. y Sanchez, C. 2001: Dicocer 2. Corpus des céramiques de l'Âge du Fer de Lattes (fouilles 1963-1999), Lattara 14.

Rambla Torralvo, J. A. y Cisneros García, M. I. 2000: "Un depósito excepcional de materiales del siglo IV a.C. en Granada", Revista de Arqueología 235, 42-49.

Rambla Torralvo, J. A. y Salado Escaño, J. B. 2002: "Hallazgos de época ibérica y musulmana junto a la Alcaicería de Granada", Anuario Arqueológico de Andalucía 1999/III-1, Sevilla, 175-185.

Roca Roumens, M., Moreno Onorato, M. A. y Lizcano Pretel, R. 1988: "El Albaicín y los orígenes de la ciudad de Granada", Monográfica arte y arqueología 2, Granada.

Rodríguez Aguilera, A. 2001: Granada arqueológica, Colección Granada y sus barrios 6, Granada.

Rodríguez Ariza, M. O. 1991-1992: "El yacimiento ibérico de Loma Linda (Los Ogíjares, Granada)", 
Cuadernos de Prehistoria de la Universidad de Granada 16-17, 353-388.

Rodríguez Ariza, M. O., Fresneda Padilla, E., Peña Rodríguez, J. M. y López López, M. 1999: “Los niveles ibéricos de Fuente Amarga (Galera, Granada)", XXIV Congreso Nacional de Arqueología, 3, Murcia, 283-292.

Román Punzón, J. M. y Mancilla Cabello, M. I. 2008: "Propuesta de sistematización de la cerámica ibérica de la Vega de Granada", A. M. Adroher y J. Blánquez (eds.), 1er Congreso Internacional de Arqueología Ibérica Bastetana, 2, Serie Varia 9, Madrid, 163-177.

Ruiz Mata, D. y Córdoba Alonso, I. 1999: “Los hornos cerámicos turdetanos del Cerro Macareno. Cortes H.I y H.II", XXIV Congreso Nacional de Arqueología, 3, Murcia, 95-106.

Rouillard, P. y de la Torre Castellano, I. 2014: "Les coupes à tige attiques de Zacatín (Grenade): premières réflexions sur un lot de vases du IVe s. av. J.-C.”, Bastetania 2, 1-14.

Rufete Tomico, P. 1988-1989: "Las cerámicas con engobe rojo de Huelva", Huelva Arqueológica 10-11, 9-40.

Sáez Romero, A. M. 2010: “Comercio, procesado y consumo. Análisis evolutivo de algunas familias cerámicas gadiritas de época púnica y tardopúnica", C. Mata et alii. (eds.), De la cuina a la taula, IV reunió d'economia en el Ier mil.lenni a.C., Saguntum Extra 9, Valencia, 303-312.
Sotomayor Muro, M., Sola, A. y Choclán, C. 1984: Los más antiguos vestigios de la Granada iberoromana y árabe, Granada.

Torre Castellano, I. de la 2005: "El depósito del Zacatín: los vidrios de núcleo de arena”, C. Vílchez et alii (coords.), Los vidrios griegos en Granada, Granada, 87-106.

Torre Castellano, I. de la 2008: "Avance del estudio de materiales del depósito del Zacatín (Granada): aproximación cuantitativa y tipológica de la cerámica del depósito", A. M. Adroher y J. Blánquez (eds.), ler Congreso Internacional de arqueología ibérica bastetana, Serie Varia 9, vol. 2, Madrid, 107-115.

Vaquerizo Gil, D., Quesada Sanz, F. y Murillo Redondo, J. F. 2001: "Protohistoria y romanización en la subbética cordobesa. Una aproximación al desarrollo de la cultura ibérica en el Sur de la actual provincia de Córdoba", Arqueología monografías 11, Sevilla.

Verdan, S., Reber, K., Kenzelmann-Pfyffer, A. y Theurillat, T. (ed.) 2011: Iron Age pottery: a quantitative approach. Round Table, Athens, 2008, BAR, Int. Series 2254, Oxford.

Vílchez Vílchez, C., de la Torre Castellano I. y Adroher Auroux, A. M. (coord.) 2005: Los vidrios griegos en Granada, Granada.

Recibido: 21-08-2014

Aceptado: 17-11-2014 